\title{
A BIM-based framework for construction project scheduling risk management
}

${ }^{1 *}$ Abanda F.H., ${ }^{1}$ Musa A.M., ${ }^{2}$ Clermont P., ${ }^{1}$ Tah J.H.M. and ${ }^{1}$ Oti A.H.

${ }^{1}$ Oxford Institute for Sustainable Development, Department of Real Estate and Construction, Faculty of Technology, Design and Environment, Oxford Brookes University, Oxford, OX3 0BP, UK

${ }^{2}$ Laboratoire Génie de Production, Ecole Nationale d’Ingénieurs de Tarbes 47, Avenue Azereix, BP 1629, F-65016 Tarbes Cedex, France

*Corresponding author: fabanda@,brookes.ac.uk

\begin{abstract}
The management of risks has been at the heart of most construction projects. Building Information Modelling (BIM) provides opportunities to manage risks in construction projects. However, studies about the use of BIM in risk management are sketchy with a lack of a systematic approach in using BIM for managing risk in construction projects. Based on existing risk models, this study investigated and developed a BIM-based framework for the management of construction project scheduling risk. Although, the frameworks were developed by mining risk management processes from Synchro and Vico, both being amongst leading 4D/5D BIM software systems, they can inform risk management in BIM projects that are supported by 4D/5D BIM software systems that contain risk management modules. The frameworks were validated for their syntactic and semantic correctness.
\end{abstract}

Keywords: BIM, Construction projects, Risk, Synchro, Vico, 4D/5D BIM

\section{Bibliographical notes}

Henry Abanda has a BSc (Hons) and Dipl.-Ing. in Mathematics/Physics and Civil Engineering, respectively. After obtaining his degree in Civil Engineering in 2003, he worked as a Project Engineer on projects funded by the governments of Cameroon and Japan. He obtained his PhD from the School of the Built Environment, Oxford Brookes University in the UK in 2011. Currently, he is a Senior Lecturer in the School and teaches Construction Project Management/Building Information Modelling at undergraduate and postgraduate levels. Also, he supervises PhD students in the area of Construction IT including Building Information Modelling (BIM). Henry has published extensively in top quality journals in the domains of BIM. 
Musa was a student of the School of the Built Environment at Oxford Brookes University while writing this paper. He graduated with an MSc in Construction Project Management. Currently, he is managing a number of construction projects in Nigeria.

Dr. Philippe Clermont holds an engineering degree from ENI (National Engineering School) of Tarbes and a doctorate of the University of Bordeaux I. Current; he is Assistant Professor at ENI of Tarbes. Since 2003, he has been the problem solving methods in France (ENIT, ESC Pau, CESI, University of Strasbourg) and abroad (ENSA of Agadir Morocco, ETS Montreal Canada, University Sabana Colombie, St Jérôme Cameroun university). He has had the opportunity of teaching the same in several companies (SEB, The Post office, Turbomeca, Airbus).

Prof. Joseph H. M. Tah is Professor in Project Management and Head of School of the Built Environment at Oxford Brookes University in the UK. He has extensive experience in the application of artificial intelligence, distributed computing, and building information modelling techniques to systems for managing large-scale projects and extended enterprises in the construction and related industries. He has published widely in these areas and provided consultancy and advisory services to national and international companies and governments. He is a Fellow of the Royal Institution of Chartered Surveyors (FRICS) and a member of the Chartered Institute of Building (MCIOB).

Dr. Henry Oti is a post-doctoral research assistant and associate lecturer at Oxford Brookes University. He worked on the FutureFit Built Assets and the BIM-enable Low Impact School Procurement (BLISP) projects funded by the European Regional Development Fund (ERDF) and Innovate UK respectively. His research interests include sustainable building development, building information modelling and management in the built environment and the integration of BIM with emerging Big/Open/Link Data for predictive decision-making and smart city applications. He has published high impact articles in the areas of BIM and integration with building management systems (BMS) to inform sustainability appraisal, building design and operation.

\section{Introduction}

Globally, the construction industry has been noted for poor project performance for generations. Amongst the different reasons, issues related with risk management contributing to the poor construction project performance has been too common (Carr and Tah 2001; Tah and Carr, 2000a; b; Tah and Carr, 2001a;b; Jannadi and Almishari, 2003). Risk quantification and analysis has been at the core of risk management for decades. The quantification of risk can guide in the justifications of the cost of measures to mitigate, transfer or avoid the risk in a construction projects. However, risk assessments and quantification techniques developed around the 1950s and 1960s were founded on operational research techniques such as Monte Carlo simulation, sensitivity analysis and decision analysis (Tah and Carr, 2000b), fuzzy sets and probabilistic theories. The computation and analytical 
challenges including implementation in practice has long been noted. This has led to the development of information and knowledge-based systems that build on the aforementioned techniques for managing risk in construction projects. With increasing complexity of modern construction projects, further exacerbated by the need to highly perform and to meet stringent clients' requirements, the aforementioned methods are limited. First such systems do not integrate the geometric project model with the non-geometric data for risk assessments. Therefore the accuracy of the geometric data being edited into the information/knowledge-based risk assessment systems highly depends on the risk assessor. Secondly, because of the disconnection between the geometric model and the non-geometric data, real-time assessment is very challenging. Thirdly, the aforementioned risk management systems are seldom designed to facilitate collaboration amongst the project stakeholders where communication and exchange of risk information can be undertaken. Emerging Building Information Modelling (BIM) provides opportunities to overcome these limitations.

BIM is gaining momentum as an efficient platform of collaboration in delivering construction projects. BIM is now at the heart of many Western government policies. It has been mandatory on government projects in Finland and Sweden. In the UK, from the $4^{\text {th }}$ of April 2016, BIM level 2 became mandatory on all centrally government procured projects. Crucial to BIM, is the seamless communication or exchange of construction information between software-software systems, software-human systems, supply chains and other entities directly or indirectly related construction projects. There has been an abundance of peer-reviewed literature with regards to developing an understanding about different construction domains through communication of information about the domains. Some examples include quantity surveying (Monteiro and Martins, 2013), cost estimation (Lee et al., 2014), project planning (Kim et al., 2015), sustainability (Abanda et al., 2014), building energy simulation (Abanda and Byers, 2016), etc. Ironically, given that risk affects all of the aforementioned domains; it has unfortunately received very limited interest from researchers. One of the reasons is underlined in Matějka and Tomek (2014) argument that the domain of risk is very subjective and is often an object of private know-how. Our effort is to explore the extent to which BIM can support the risk management process. Communicating risk (or communication for short) is 
at the heart of risk management. However, as argued in Tah and Carr (2000a; b), communication project risk is poor, incomplete and inconsistent both throughout the supply chain and through the project life cycle. Even the term risk appears to be lack of consistency. It is easily being used interchangeably with terms like "hazard" and "uncertainty" (Jannadi and Almishari, 2003). This characterisation of project risk is partly related to the lack of a formalised approach to project risk management. Previous efforts (e.g. Carr and Tah 2001; Tah and Carr, 2000a;b; Tah and Carr, $2001 \mathrm{a} ; \mathrm{b})$ that led to the development of formal approaches have topped download charts in their respective journals and also cited significantly in many other peer-reviewed papers signifying the importance of the domain. However, perhaps partly because of the emerging nature of BIM, similar studies about systematised formal BIM-based risk management approaches are scarce. This is corroborated by Araszkiewicz (2015) that "risk is an issue in the concept of BIM that still needs to be systematized." While there has been a growing amount of evidence suggesting the need for further research exploring the synergies between BIM and risk management techniques (e.g. Araszkiewicz (2015) and Malekitabar et al. (2016)), issues related to scheduling risk has often been overlooked. A recent study by Hwang and Ng. (2013) that investigated project-related challenges, the respondents ranked schedule management and planning as the most important knowledge area, followed by risk management. Also, a recent study by Zhang et al. (2014) argued that scheduling risks are the main threat for high efficiency of scheduling management in power grid engineering. Therefore the aim of this study is to explore BIM for scheduling risk management with an ultimate goal of developing BIM-based frameworks for construction scheduling risk management.

To facilitate understanding, the remainder of this paper is divided into 7 sections. To provide the context of this study, other related studies about the domain of risk management in construction and BIM applications in risk management are explored in section 2 . In section 3 , the methods used to achieve the aim of this study are examined. In section 4, the theoretical models that underpin this study were examined. This is followed by an assessment of 4D/5D BIM software systems, where emphasis was placed on the type of operating systems supporting the software, the import/export file formats of the software and whether risk has been integrated into the software in section 5. In section 
6, a Synchro-BIM-based approach for risk management is proposed followed by a similar Vico-BIMbased in section 7. The Synchro and Vico - based- approaches culminated in the development of frameworks that include detail steps and information required at some key points in scheduling risk management. An effort to generalised the framework through integration is undertaken in section 8 . The validation of the proposed framework is discussed in section 9. The paper concludes by a way of summary in section 10 .

\section{Other related studies}

In order to gain an insight into the domain of construction risk management and the domain of BIM, an extensive literature review was undertaken. Also, the aim of this review was to establish the knowledge gaps that served as the basis for the rationale of this study. The study of risk in construction is as old as the age of the construction industry. Without any specific constraint on timeline, studies stretching back as far as at least three decades are still too common in many peerreviewed scientific databases. Levitt et al. (1980) developed a quantitative risk analysis model that incorporates differing risk perceptions, the positive "incentive" value of accepting controllable risks, and alternative incentive systems. Kangari and Boyer (1981) developed methods of selection of construction projects under risk. d'Albe (1982) developed an approach in managing earthquake risks. Cooper et al. (1985) proposed a risk analysis approach of construction cost estimate for large hydroelectric projects. Perhaps, partly because of the importance of risk impacts on construction projects, interest in research in risk management has been on the rise. Some recent studies include (Ameyaw et al., 2015; Chen et al., 2014; Chen et al., 2015). Chen et al. (2014) applied an improved Analytic Hierarchy Process in the risk management of tunnel construction. Ameyaw et al. (2015) identified and then evaluated perceived risk factors influencing variability between contract sum and final count, and developed a fuzzy risk assessment model for evaluating the overall impact of established critical risk factors impacting on variability between contract sum and final account in government-funded construction projects. Chen et al. (2015) explored the relationship among decision makers' risk perception, risk propensity, and their bid/no-bid decision making of construction projects, as well as the factors influencing the risk perception and propensity. The list of publications about risk management within the last 3-4 decades is huge and cannot be considered on case by case 
basis. Given the scope of this study, an extensive search on BIM-based risk management studies was conducted in major journal databases and Google search engine. Since the recommendation about the need to integrate risk into $\mathrm{nD}$ BIM modelling systems was made by Tah et al. (undated), concrete studies on how to systematically simulate risk in an $\mathrm{nD}$ modelling environment is lacking. The few studies are Wu et al. (2015), Musa et al. (2015), Hammad et al. (2015), Sun et al. (2015), Zou et al. (2015), Malvar and Likhitruangsilp (2015). Wu et al. (2015) developed a BIM-based risk analytical system for monitoring risk associated with deep excavation projects. It is important to note that the preceding study did not consider scheduling. Musa et al. (2015) and Hammad et al. (2015) investigated and illustrated how BIM can reduce internal risk in construction delivery process. Sun et al. (2015) developed a BIM-based construction project cost and schedule risk early warning model for effective management of construction project risks. Malvar and Likhitruangsilp $(2014 ; 2015)$ developed a framework for mapping BIM uses against critical construction risks that was implemented on Design-Build projects in the Philippines. However; the study did not provide a systematic framework for managing the risks. A study by Zou et al. (2015) explored the challenges associated with the management of risk using emerging BIM and concluded that one of the most significant problems is the lack of a theory aligning BIM with risk management to support the development process of a project. The authors extended their effort in conducting an extensive literature review about risk management using technologies including BIM (Zou et al., 2016). A major finding from the study revealed that BIM could be used to support project development process and could serve as a core data generator and platform to allow other BIM-based tools to perform further risk analysis. The study fell short of providing a framework for undertaking the risk analysis in a BIM environment.

What emerges from this overview is the urgent need to develop a structured BIM-based framework (s) for the management of risk in construction projects. The need for such a framework (s) has been echoed by Araszkiewicz (2015). The frameworks facilitate systematic identification, analysis, evaluation and monitoring of risk; and above all should be easy to implement by end-users. 
Furthermore, the proposed frameworks reveal BIM and non-BIM-based risk management activities and guidelines on how they should be undertaken.

\section{Research Methods}

In order to achieve the aim of this study, a number of methods were pursued as presented in Figure 1.

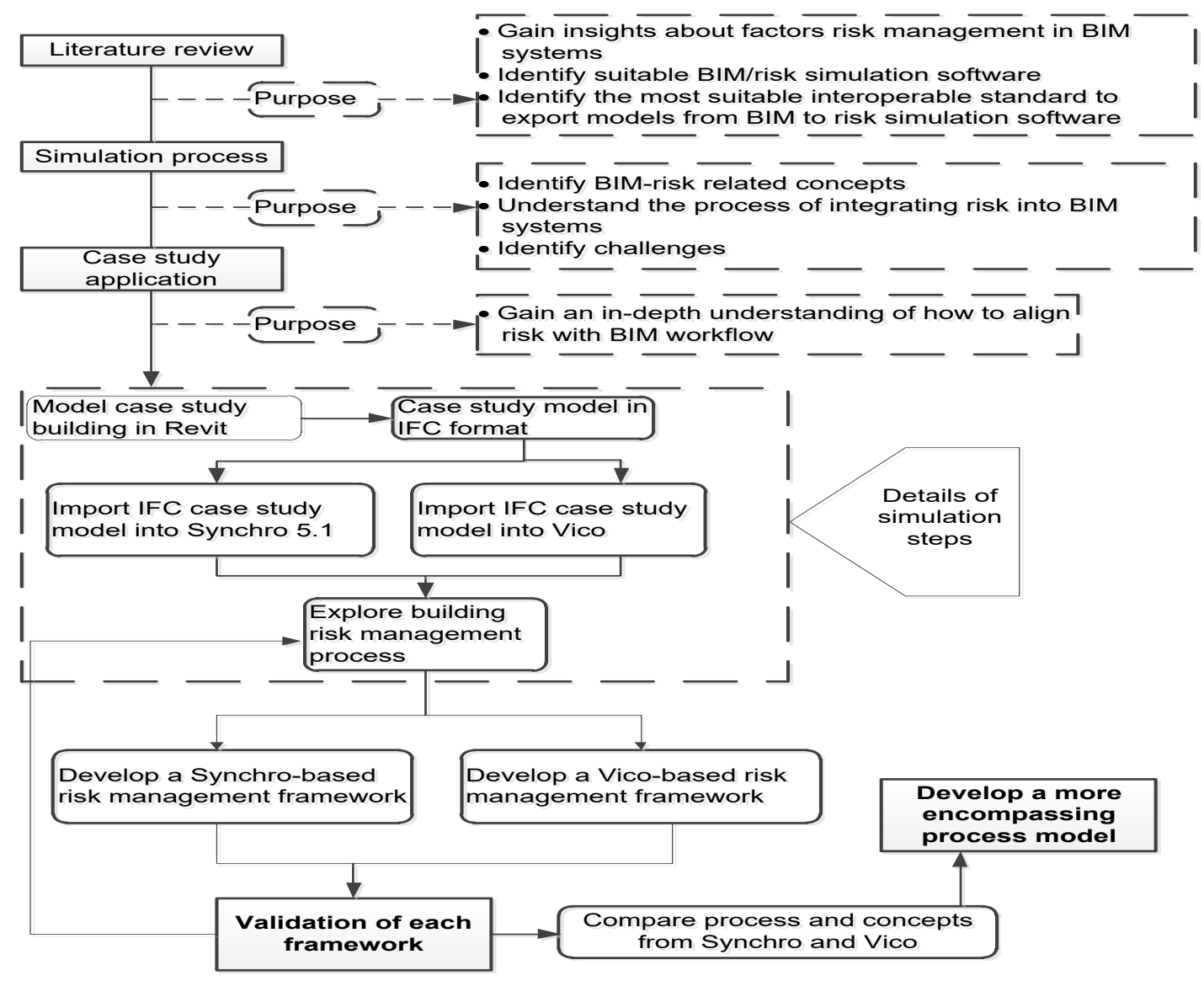

Figure 1 Research design

The study commenced with an in-depth literature review to understand the BIM and risk management domains. The extensive search of scientific journal databases led to the identification of very few BIM-related studies (Wu et al. 2015; Musa et al. 2015; Hammad et al. 2015; Sun et al. 2015; Zou et al. 2015; Malvar and Likhitruangsilp 2015). Thus it was imperative to adopt an exploratory approach using case studies which generally allows for in-depth investigation of a domain with limited literature (Oates, 2006). A typical building with well-known information was chosen and modelled in a BIM authoring tool before exported to BIM-based risk simulation software. The export was facilitated by the use of the Industry Foundation Classes (IFC). Based on studies by Abanda et al. (2015), two most widely used 4D/5D BIM software systems, Synchro and Vico were chosen as case studies for the simulating the risks. Computer simulation is growing significantly as a methodological approach for researchers (Dooley, 2002). A simulation experiment is considered an attempt to bring the real world into a computer environment to increase the validity of experimental results. In this 
kind of research the researcher builds up a model that simulates reality (Ihrig, 2012). Simulation answers the question "what if?" it allows the researcher to move forward into the future, unlike other methods, and to study more complex systems to observe every angle of it (Dooley, 2002). The simulation processes in Synchro and Vico were iterative with detail analysis on the steps using the software systems discussed. The analysis of the steps led to the development of each software-specific framework. This culminated in the development of a more encompassing framework from both the Synchro and Vico-based frameworks. In developing the framework, the Business Process Modeling Notation (BPMN) (http://www.bpmn.org/) has been used. The relevant BPMN symbols used have been presented in Figure 2. The definitions of the different notations have been taken from http://www.bpmn.org/; thus will not be duplicated here.

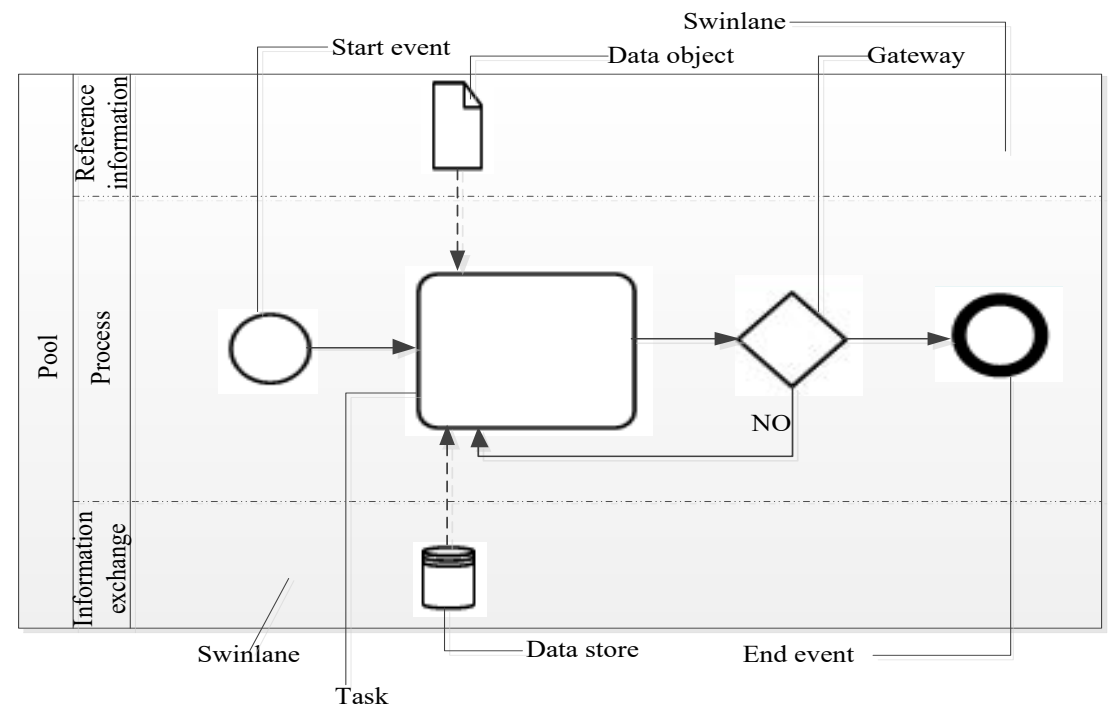

Figure 2: BPMN components' notations used in risk management process model

The symbols presented in Figure 2 were employed for the development of the frameworks using Bizagi, an open source process modelling tool. Bizagi was also used in validating the syntatic correctness of the frameworks. Furthermore, three experts were used in validating the semantic correctness of the frameworks.

\section{Risk management techniques in construction: A conceptual framework}

In project management, many risk management tools have been proposed. The major common tools are Project Risk Analysis and Management (PRAM), Shape, Harness, and Manage Project Uncertainty (SHAMPU) and Risk Analysis and Management of Projects (RAMP). Furthermore, risk management have been included in generic project management tools such as The Project Management Body of Knowledge (PMBOK) and Prince2. The different risk components in these 
tools are presented in Figure 3. The components have been used to develop a more encompassing risk management process presented in the extreme left of Figure 3.

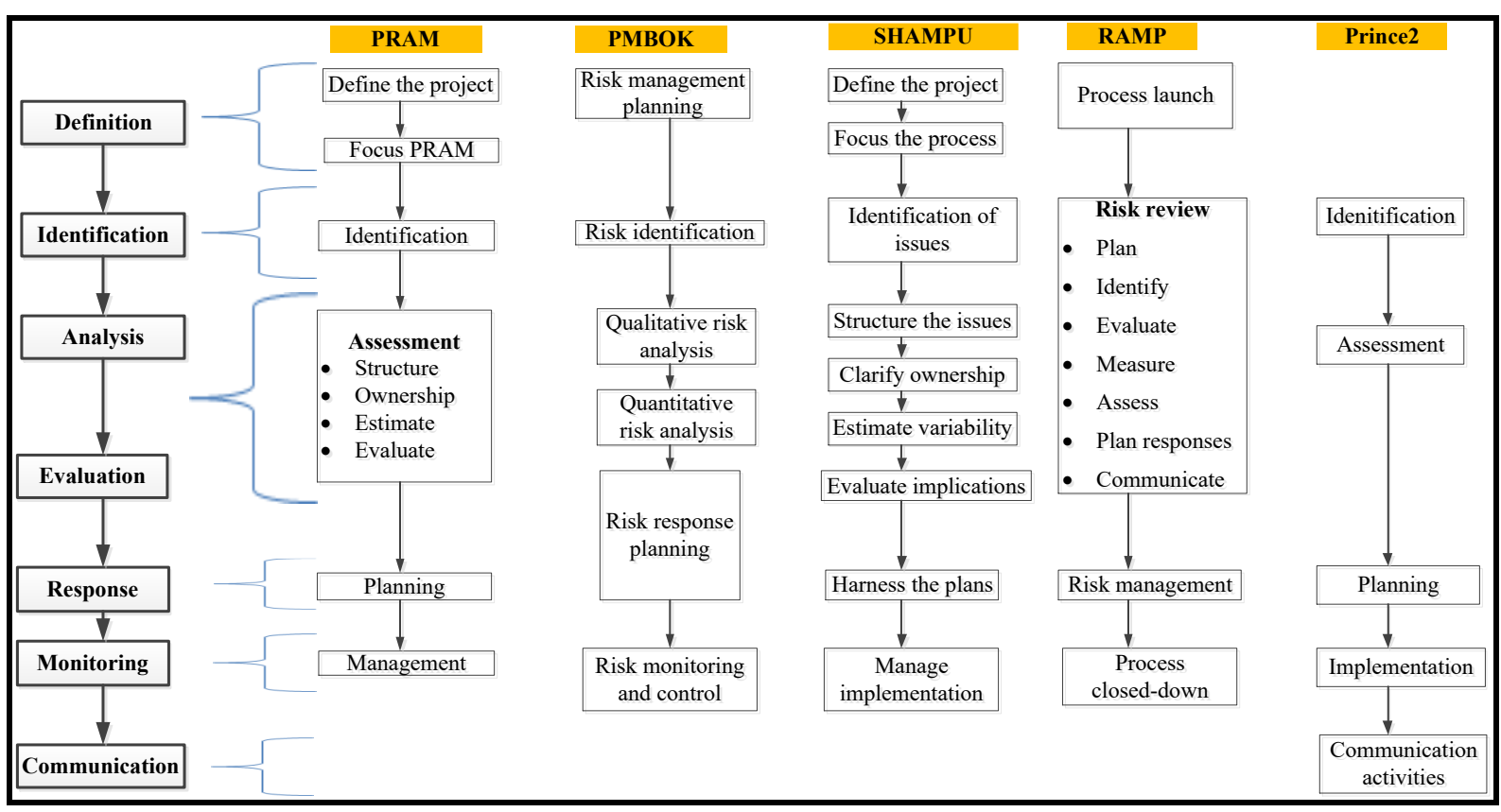

Figure 3 A conceptual risk management framework [Adapted from Niño et al. (2014)]

Based on the theoretical models in Figure 3 and that of Tah et al. (undated), the key risk management procedures are risk definitions, risk identifications, risk analysis, risk evaluation, risk response, risk monitoring and risk communication generalised on the extreme left. To facilitate understanding, a brief overview of the generalised risk management procedures will be examined in the ensuing paragraphs.

Risk definitions: Prior to any effective good risk management, it is imperative to understand the nature of risks and their behaviours. Risk is said to be any event or condition which is uncertain whereby its occurrence causes an effect on project objectives (PMI, 2013). Such objectives include scope, schedule, cost and quality. Risks are inclusive of threats (unfavourable risks) and opportunities (favourable risks), as such it is mandatory to be able to describe or specify and understand risks that could either affect a particular project negatively or positively. Based on sound risk definition, critical risk response decisions on threats and opportunities can be made to enhance effective risk management. 
Risk identifications: This basically involves the process of deciding or establishing certain risks that have the potential of affecting a project and documenting their features (Nieto-Morote and Ruz-Vila, 2011). Ghazali and Kabir (2009) investigated the risk identification process of the Leeds Mental Health Trust (LMHT) hospital PFI project relocation scheme. The study found out that the technique adopted for identifying the numerous risks that could affect the project was brainstorming. In addition to brainstorming, Kansal and Sharma (2012) identified a number of risk identification techniques which include: Delphi technique, interview/expert judgement, checklist, influence diagram, flowchart as well as cause-and effect diagrams. Risk identification has proven to be an essential action in risk management.

Risk analysis: Risk analysis is the action or measures taken to provide an estimate or assessment of the possible outcomes or effects of risks likely to transpire in a project (Baloi, 2012). Risk analysis is categorised into qualitative and quantitative techniques. According to De Marco and Thaheem (2014), qualitative analysis focuses on qualitative description and degree (consisting of high, medium and low) of probability and impact of risk consequences. On the other hand quantitative analysis gives numerical analysis of the effect of the identified risks on the project deliverables.

Risk evaluation: Risk evaluation seeks to make sound judgements as well as prioritising risks that need immediate action as a result of the analysis undertaken (Niño et al, 2014). This aspect of risk management entails examining and combining the overall probability of occurrence of the risks (Nieto-Morote and Ruz-Vila, 2011).

Risk response: The overall motive for risk response is to minimize the intensity of a negative risk on a project and in the case of a positive risk - which serves as an opportunity- the goal is to maximise its benefits (Van Wyk et al, 2008). Furthermore, forms of risk response include: risk reduction, transfer, avoidance and retention or a combination of all. Sangsomboon and Yan (2014) investigated the risk response measures employed by contractors of railroad projects in Thailand. The study showed that 
risk reduction, risk retention and risk transfer are the most common risk response measures adopted. Risk response is that crucial aspect of risk management that exudes good and effective risk management.

Risk monitoring: Since construction risks cannot be totally eliminated, risk monitoring involves the continuous operative overseeing of risk control measures so that effective risk management does not fall short of the needed standard (Schieg, 2006). Besides the monitoring of the identified and analysed risks, it is equally important to check out and observe the likely emergence of residual risks as well as identifying new risks. Peterson (2009) examined how safety risk was monitored by Frankford Hospitals, Philadelphia to limit effect of renovation construction activities on patients, employees and vendors. By implementing infection control risk assessment (ICRA) monitoring, potentially hazardous situations were averted which reduced construction safety risk to patients and staff.

Risk communication: According to London's King's College research report (HSE, 2010), risk communication encompasses a collaborative process of information exchange on opinions among individuals or groups. This is fully characterised by a two-way relay of information on nature of risks together with opinions and reactions to risk messages for sufficient risk management. Communication of risk is essential in risk assessment process and the Management of Health and Safety at Work Regulations 1999 mandated that risk and risk controls must at all times be communicated to those undertaking tasks and those likely to be affected by the work (Highways Agency, 2013). Therefore, to achieve the maximum benefits of the planned and implemented risk management process, a steady risk communication chain needs to be maintained at all times throughout the lifecycle of any construction project.

The proposed BIM - risk management technique (s) will build on the risk management procedures discussed in the preceding paragraph. Before embarking on the technique(s), it is important to justify the chosen BIM - based software systems required for this study, 


\section{BIM technologies for risk management}

It was imperative to identify suitable BIM software systems for the simulation of risks. The study by Musa et al. (2015) investigated different traditionally scheduling software (e.g. Primavera, MS Project, Asta Powerproject) and identified those that could be used for risk management. However, these traditional scheduling software systems cannot contain geometric model. A recent study conducted by Abanda et al. (2015) led to the identification of/and differences between 122 BIM software systems across different construction domains. However, the study was top level with limited focus and details on whether the software could be used for modelling risk. Building on Musa et al. (2015) and Abanda et al. (2015) we conducted a detailed analysis of only 4D/5D BIM software systems to identify the most relevant for this study (see Table 1).

Table 1: An overview of 4D BIM software systems [adapted from Musa et al. (2016)]

\begin{tabular}{|c|c|c|c|c|}
\hline Software & Export formats & Import formats & $\begin{array}{l}\text { Risk } \\
\text { analysis }\end{array}$ & $\begin{array}{l}\text { Operati } \\
n g\end{array}$ \\
\hline Autodesk Navisworks & $\begin{array}{l}3 D D W F, D W F x, F B X \\
K M L, N W D, N W F\end{array}$ & $\begin{array}{l}T X T, A S C, D G N, P R P, P R W, D W F, \\
D W F x, W 2 D, D W G, D X F, F B X, I F C \text {, } \\
R V T, S K P, N W D, N W F, N W C\end{array}$ & No & $\begin{array}{l}\text { Window } \\
s\end{array}$ \\
\hline AVEVA NET Player & $\begin{array}{l}X M L, P D F, P P T, H T M L \\
S V G, D O C\end{array}$ & $H T M L, X L S, X M L, S V G$ & No & $\begin{array}{l}\text { Window } \\
s\end{array}$ \\
\hline Bentley ConstructSim & $X L S, I F C$ & $\begin{array}{l}\text { ISO, XLS, DGN, DWG, PDS, PDMS, } \\
\text { IGES, IFC }\end{array}$ & \multirow{2}{*}{ Yes } & $\begin{array}{l}\text { Window } \\
s\end{array}$ \\
\hline Bentley Navigator & $I F C, P D F$ & $\begin{array}{l}I F C, D G N, D W G, D X F, S K P, P D F, I G E S, \\
K M L, X M L, X E R\end{array}$ & & $\begin{array}{l}\text { Window } \\
s\end{array}$ \\
\hline $\begin{array}{l}\text { Dassault Systemes } \\
\text { CATIA }\end{array}$ & $\begin{array}{l}3 D X M L, D W G, D X F \\
P D F, I G S\end{array}$ & $3 D X M L, D X F, C A T P r o d u c t, I G 2, I G S$ & No & $\begin{array}{l}\text { Window } \\
\text { s/Linux/ } \\
\text { Unix }\end{array}$ \\
\hline $\begin{array}{l}\text { Dassault Systemes } \\
\text { Civil Design for } \\
\text { Fabrication }\end{array}$ & $I F C$ & $I F C$ & No & $\begin{array}{l}\text { Window } \\
s\end{array}$ \\
\hline $\begin{array}{l}\text { Dassault Systemes } \\
\text { Delmia }\end{array}$ & IFC & $X M L, X E R, I F C$ & No & $\begin{array}{l}\text { Window } \\
\text { s/Unix }\end{array}$ \\
\hline $\begin{array}{l}\text { Dassault Systemes } \\
\text { Optimized Planning }\end{array}$ & IFC & $I F C$ & No & $\begin{array}{l}\text { Window } \\
s\end{array}$ \\
\hline $\begin{array}{l}\text { Digital Project } \\
\text { Extensions }\end{array}$ & $I F C, X M L, H T M L$ & $I F C, X E R, X M L, D W G, D X F, I G E S, S D N F$ & No & $\begin{array}{l}\text { Window } \\
s\end{array}$ \\
\hline $\begin{array}{l}\text { D-Studio 4D Virtual } \\
\text { Builder }\end{array}$ & $4 D P P T, I F C$ & $X M L, M P P, M D P, P P, I F C$ & No & $\begin{array}{l}\text { Window } \\
s\end{array}$ \\
\hline
\end{tabular}




\begin{tabular}{|c|c|c|c|c|}
\hline $\begin{array}{l}\text { DESTINI Profiler } \\
\text { (Beck Technologies) }\end{array}$ & $\begin{array}{l}D W G, D X F, e Q U E S T \\
\text { IFC, IGES, KML/KMZ, } \\
\text { STL, XLS }\end{array}$ & $P D F, D W G, D X F, X L S, R V T, P E E, M C 2$ & No & $\begin{array}{l}\text { Window } \\
S\end{array}$ \\
\hline $\begin{array}{l}\text { Innovaya } 4 D / 5 D \\
\text { Simulation and } \\
\text { Estimating }\end{array}$ & $I N V, H T M L, D O C$, & $X M L, I N V, X E R, X L S, R V T, M P X, D W G$ & Yes & $\begin{array}{l}\text { Window } \\
s\end{array}$ \\
\hline $\begin{array}{l}\text { Intergraph SmartPlant } \\
\text { Construction }\end{array}$ & $X E R, I F C$ & $\begin{array}{l}X E R, X M L, I F C, D W G, D X F, D G N, P D S, \\
\text { PDMS, CAESAR II, SAT, XMpLant, } \\
\text { CADWorx }\end{array}$ & No & $\begin{array}{l}\text { Window } \\
s\end{array}$ \\
\hline $\begin{array}{l}\text { Onuma Planning } \\
\text { System }\end{array}$ & $\begin{array}{l}\text { GBXML, IFC, COBie, } \\
\text { KML, BIMXML, } \\
\text { CityGML }\end{array}$ & $\begin{array}{l}\text { IFC, OGC, OSCRE, COBie, XLS, KML, } \\
C S V, G B X M L, X M L, B I M X M L, C i t y G M L\end{array}$ & No & $\begin{array}{l}\text { Window } \\
\text { s/Mac/L } \\
\text { inux }\end{array}$ \\
\hline Solibri Model Checker & $\begin{array}{l}I F C, P D F, R T F, X L S, \\
S M C\end{array}$ & $I F C, D W G, D X F, D G N, S K P, S M C$ & No & $\begin{array}{l}\text { Window } \\
\text { s/Mac }\end{array}$ \\
\hline Synchro Software & $\begin{array}{l}S P, X M L, X E R, I F C, \\
X L S, P 3\end{array}$ & $X M L, P 3, X E R, I F C, S P, N P 4$ & Yes & $\begin{array}{l}\text { Window } \\
s\end{array}$ \\
\hline Tekla Structures & $\begin{array}{l}P D S, X M L, P M L, S C I A \\
H L I, D W G, D X F, D G N, \\
I F C, S D N F, S K P, P D M S\end{array}$ & $I F C, D W G, D X F, D G N, X M L, H L I, S D N F$ & No & $\begin{array}{l}\text { Window } \\
S\end{array}$ \\
\hline $\begin{array}{l}\text { Vico Virtual } \\
\text { Construction }\end{array}$ & $X M L, X L S, D O C, P D F$ & $\begin{array}{l}I F C, S K P, D W G, s b X M L, X L S x, X M L \text {, } \\
C A D-D U C T\end{array}$ & Yes & $\begin{array}{l}\text { Window } \\
s\end{array}$ \\
\hline RIB $i T W O$ & $\begin{array}{l}I F C, X M L, X E R, M P X, \\
R P A, R P D\end{array}$ & $I F C, X M L, X E R, M P X, X L S, R P A, R P D$ & No & $\begin{array}{l}\text { Window } \\
\text { s/Mac }\end{array}$ \\
\hline Visual $5 D$ & Avi, mpeg & Cinema $4 d$, Blender, $3 d s$ max,.$R V T$ & No & $\begin{array}{l}\text { Window } \\
s\end{array}$ \\
\hline $\begin{array}{l}\text { Asta Powerproject } \\
\text { BIM }\end{array}$ & $\begin{array}{c}\text {-Asta Powerproject files } \\
(. p p)\end{array}$ & IFC & Yes & $\begin{array}{l}\text { Window } \\
s\end{array}$ \\
\hline
\end{tabular}

What emerges from Table 1 is that there are not many 4D/5D BIM software systems that contain risk management modules. Therefore, the choice was very limited and Synchro 5.1 and Vico were chosen.

\section{The proposed BIM risk management: A Synchro-based approach}

\subsection{Definitions of related terms in Synchro}

When carrying out risk management process in a BIM environment (in this case Synchro), it is important to contextualise some risk related terminologies as used in the software. The following will be discussed:

- $\quad$ Subtractive risk: This type of risk decreases the duration required to execute a particular task. This is normally a risk that has a positive effect rather than a negative effect on the task at 
hand. Once such a risk is assigned to a task, it is denoted by a negative (-) sign to indicate the type of risk assigned to that particular task or tasks.

- Additive risk: This type of risk has a negative effect by increasing the duration required to execute a particular task. Once assigned to a certain task or tasks, such task(s) takes up a positive $(+)$ sign.

- Unmitigated risk status: When a risk status is set as unmitigated, it means that that potential risk will have a definite effect on that task to which it is set to affect. In such a case, the risk has been accepted to affect the construction project as no measure is taken to mitigate it.

- $\quad$ Mitigated risk status: This risk status for a particular risk indicates that such a potential risk has been curbed and as such cannot have an effect on a particular task. In such a scenario, the risk in question is avoided.

- Buffered risk status: When a risk is buffered, it is not mitigated; rather it is transferred to another task that will absorb the risk. This task that absorbs the risk is referred to as the risk buffer. The risk buffer absorbs the risk without having a direct effect on the succeeding task or activity. When transferring a risk to a buffer, the risk buffer needs to be a downstream task because risks cannot be transferred upwards but rather downwards.

\subsection{Preliminary activities in Revit, Asta Powerproject and Synchro}

A pre-requisite for the analysis and management of risk in Synchro is the design of the building project in Revit and the planning of the schedule of activities for the project. The project schedule can be done in any software like Asta Powerproject, Microsoft project, Primavera or any other BIM compliant software. Notwithstanding, it is possible to also produce the project schedule directly in Synchro. The building model can be exported to Synchro through IFC. Furthermore, the produced project schedule can be exported (from the scheduling software) into Synchro using an XML file format. By exporting, it means that the file must have been 'saved as' an XML format and launched in Synchro in that same format. The import from both Revit and the scheduling software into Synchro is the basic and foremost action towards risk modelling in Synchro. By doing this, the various identified 
risks can then be assigned to the schedule of activities or tasks which can then be linked to the 3D model.

\subsection{Modelling risk in Synchro}

Risks are known to be uncertainties either favourable (opportunities) or unfavourable (threats) that can affect the outcome of a particular project. As illustrated in Figure 3, the general model for risk management encompasses risk identification, analysis, evaluation, response, monitoring and communication. The manner and process for carrying out these whole procedures in a BIM environment is explored in the ensuing sections.

\subsubsection{Risk Definition}

The whole process could and should be properly documented to provide a knowledge based resource. This is so as to enhance effective knowledge management which could - at all times - be referred back to; should the need arise for proper and effective risk management. Although such knowledge based resource is not enabled in Synchro, the advent of BIM and Common Data Environment (CDE) makes this achievable. CDE is said to be a single source of information for graphical, non-graphical, structured and unstructured data that could be in different locations and format but connected to this single source (BIMaaS 2015; BSI 2013). This enhances collaborative practices amongst project actors, ensuring that duplications and mistakes are reduced to the barest minimum.

\subsubsection{Risk identification}

In the context of risk management in a BIM environment (Synchro in this case), specifically project schedule related risk; the first point of call is to understand and identify those risks that can directly have an effect on the time schedule of the project. This ultimately leads to the creation of a risk register. Identifying the various possible risks can be done from using past project reports and documents. Also this can be done through 'brainstorming' exercise by the project team. In identifying these risks, it is important not to focus on just negative risks since some risks can also have a positive 
effect on a project. The identified risks are then introduced into Synchro from which the risk register can then be developed. For purposes of this study, the different types of construction risks were elicited from different the literature is presented in Appendix 1. The risks in Appendix 1 were manually edited into Synchro.

The risk register that is generated eventually is dependent upon the linking of the risks to the project tasks and the analysis of the identified risks in terms of both qualitative and quantitative analysis. It is upon completion of this procedure that the risk register is created in Synchro's risk register. Figure 4 illustrates the identified risks in this case linked to project tasks.

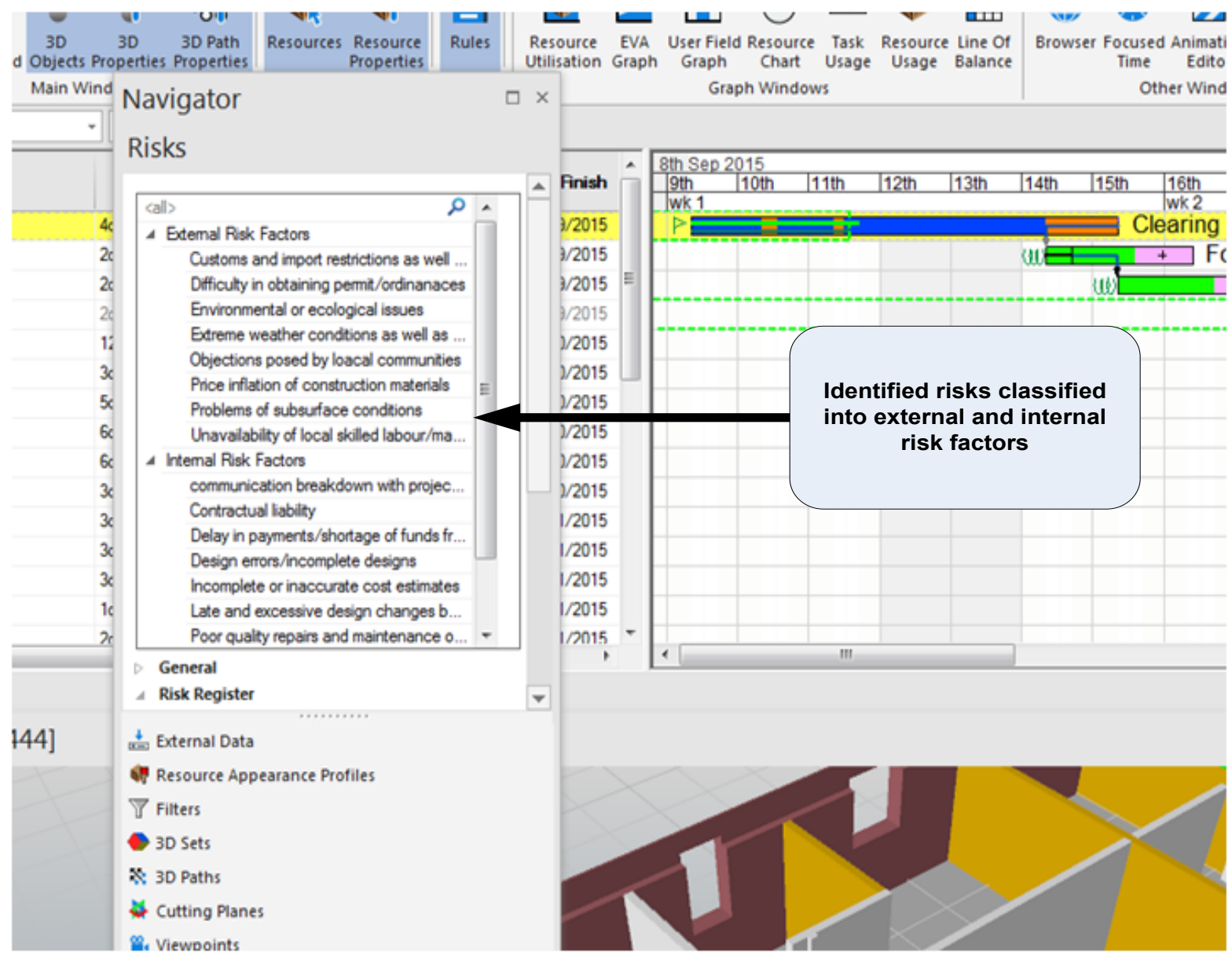

Figure 4 Identified risks incorporated into Synchro [Edited from Appendix 1]

\subsubsection{Risk analysis}


This part involves two principal aspects of analysis which includes both qualitative and quantitative risk analysis as discussed in section 4. Qualitative analysis gives a descriptive analysis of the risks in terms of risk type (whether subtractive or additive), likelihood or probability of occurrence, and risk status (whether unmitigated, mitigated or buffered). The risk type is based on whether risk is taken to be an opportunity or threat. Another aspect of the analysis considers the probability or likelihood of occurrence of the risks which is the risk weighting. This is graded in terms of low (having minimal chance of occurrence), medium (having a 50/50 chance of occurrence) or high (having a great chance of occurrence). Risk status analyses how risks are dealt with. The properties of the various risks are all included in the eventual risk register in Synchro. Figure 5 illustrates the qualitative and quantitative analysis for a particular task.

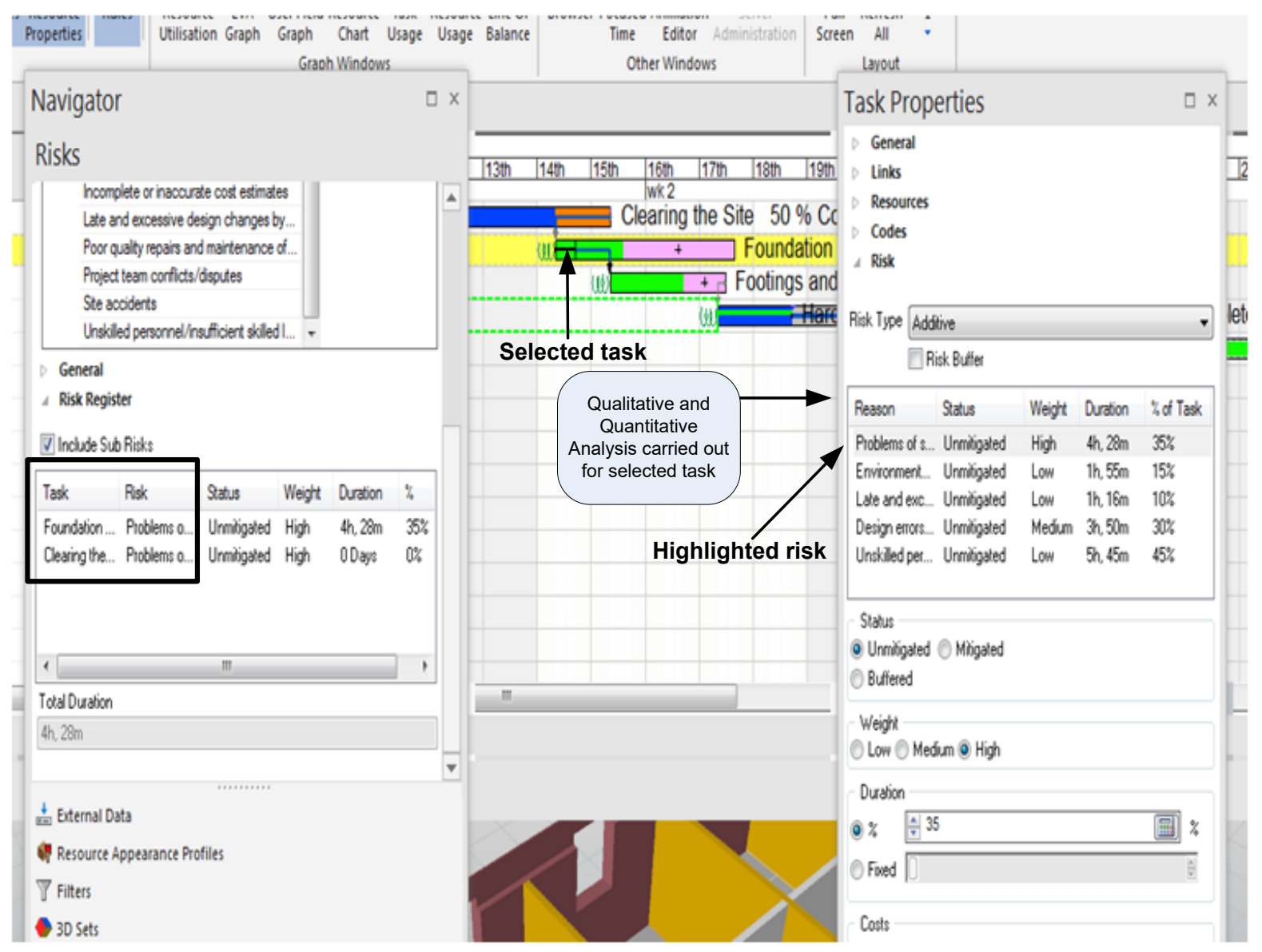

Figure 5 Qualitative and quantitative analysis

As indicated in Figure 5, quantitative analysis involves assigning values to the identified risks in terms of percentages (of a related task schedule) or fixed values. When percentages are assigned, it 
specifies the percentage duration of task(s) that can be added on task(s) leading to time overrun. Also, it specifies time reduced on tasks resulting in project running ahead of schedule than initially planned (e.g. $45 \%$ of task duration). Assigning fixed values on the other hand is attributing duration directly to task(s) as a result of the risk impact instead of a percentage (e.g. 2days or 8hours). It is important to note that the analysis must be carried out for each assigned risk to a particular task. From Figure 5, the risk type, status and weight shown are for the highlighted risk amongst the list of risks associated to that selected task. Additionally, once a risk assigned to a task is highlighted or rather selected, it shows other tasks that have been assigned to be affected by that risk. This is the case as shown by the black outlined box in the 'Navigator' window in Figure 5. In this case, it shows that two other tasks are affected by it. Upon completion of the analysis and after the risks must have been already assigned to the tasks, Synchro ultimately generates a risk register. The register provides information on the analysis carried out and the tasks affected by the risks. The impact of the risks on the overall schedule of the project is provided by the risk register, showing the schedule or time overrun that the construction project could face. Figure 6 illustrates the generated risk register.

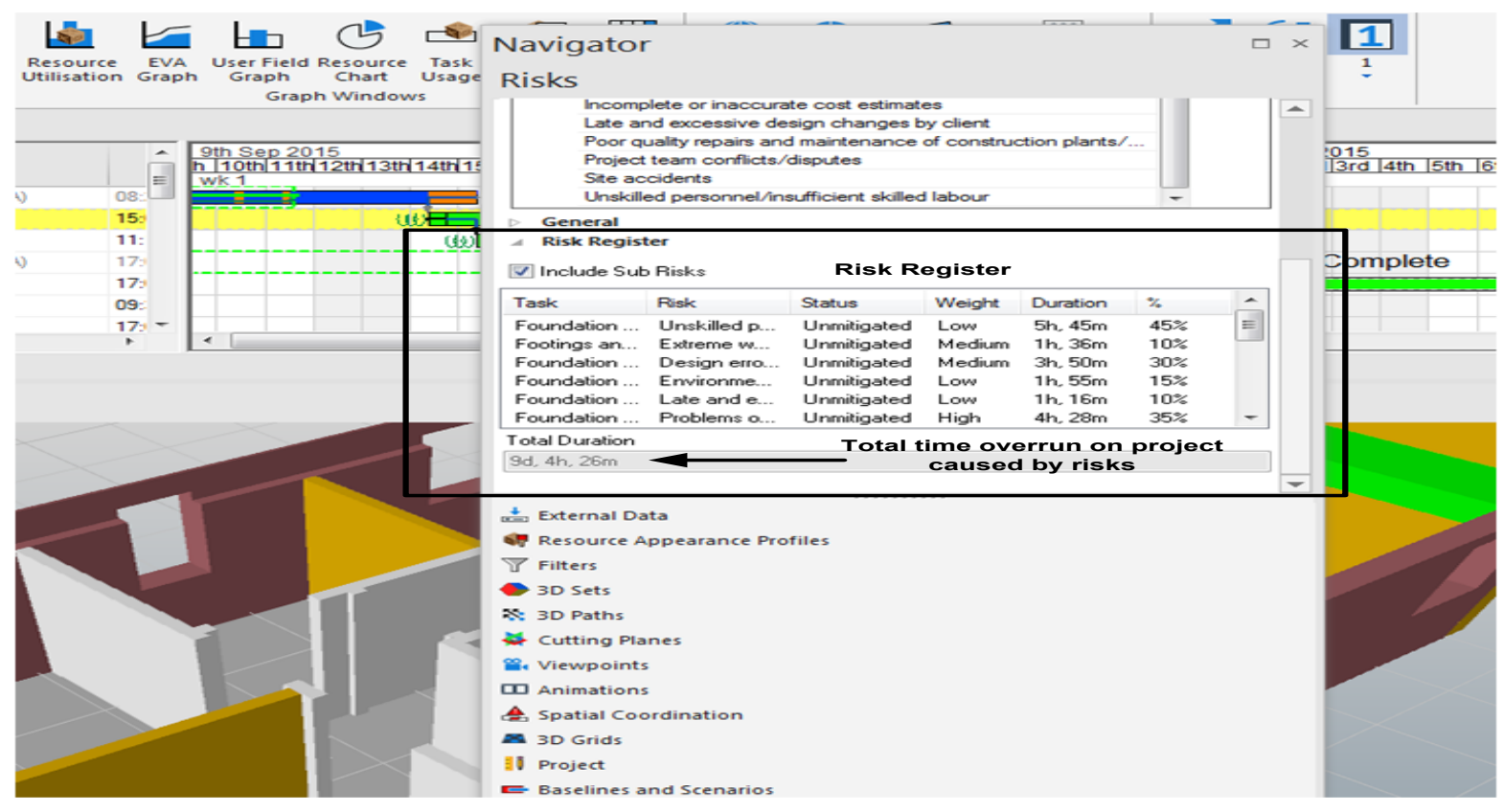

Figure 6 Generated risk register 
Once the identified risks have been fully analysed, the project tasks can then be simulated by starting the tasks and incurring the risks assigned to them. This provides a virtual visual scenario of the construction project and how it behaves as a result of the incurred risks.

\subsubsection{Risk Evaluation}

Risk evaluation aims at addressing risks according to their relative importance based on the results of the risk analysis carried out. Risks with greater possibility of occurrence as well as those likely to have higher impacts on the projects are highly prioritised. Therefore, from Figure 6, the risk register generated by Synchro should be greatly scrutinised to prioritise risks with higher probability of occurrence, having a tendency of impacting greatly on the schedule of the construction project for effective risk response. Hence, more attention and resources will be dedicated towards minimising such risk(s) to the barest minimum. It is fundamental to understand that poor or inadequate risk evaluation affects the risk response aspect of risk management. This is because, more time and resources could be dedicated to risk(s) that have lesser chances of occurrence and impact on critical objectives of the construction project.

\subsubsection{Risk Response}

Having identified, analysed and evaluated the risks likely to affect a particular project, effective risk management is reflected by the measures taken in order to react to such risks. This is where the risk response aspect of risk management evolves. Literatures such as Tah et al (undated), Van Wyk et al. (2008) and Buehring (2012) have acknowledged risk response measures such as avoiding, reducing, transferring and accepting risks for those risks that are threats, whereas exploiting, enhancing and rejecting for those ones that come as opportunities. Risk response is a direct action on the risk itself and BIM does provide the required information for determining the response needed to tackle the available risks. With respect to Synchro, the defined statuses of risks such as mitigated, unmitigated and buffered in different virtual scenarios help to provide an understanding of the risks in these scenarios. Consequently, these scenarios as a result do not tell the best risk response measures to be adopted, but through the facts provided, the best possible risk response can be adopted. Therefore, the 
various risk response measures can be determined through the statuses of risks assigned to the various risks. By so doing, through mitigation, a particular risk in question can be said to have been totally avoided or reduced to the barest minimum that it can likely have no major implication on the project schedule. By unmitigated i.e. not mitigating a particular risk, such risk can be said to have been accepted (in the case of a threat) or exploited (in the case of an opportunity). In the case of buffering a risk, such risk is said to be transferred to a later task to come in the future i.e. a downstream task in the project schedule. In this case, risks that are buffered to other task(s) can be seen as reduced because the impact of such risks would not have an impact on the overall project schedule. Figure 7 illustrates these scenarios in tasks.

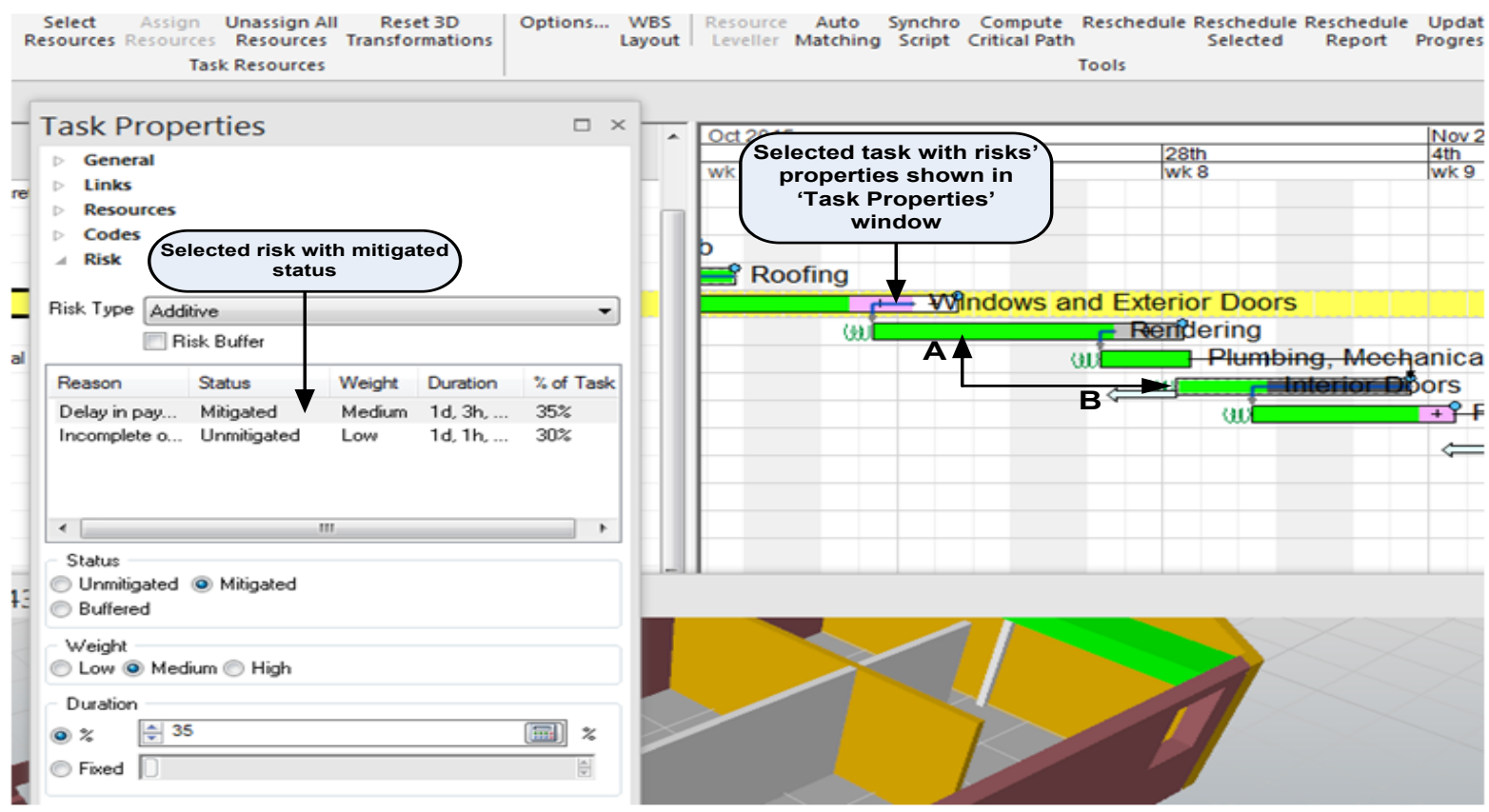

Figure 7 Mitigated, unmitigated and buffered risks in task

As shown in Figure 7, the selected task (windows and exterior doors) has two assigned risks. One of the risks is mitigated while the other is unmitigated as shown in the task properties window. In the Gantt chart window, such statuses for risks are represented using colours where pink represents unmitigated while white (towards the end of the windows and exterior doors task) represents mitigated. These colours are indicated for the selected task of windows and exterior doors. Additionally, when a risk is buffered from one task to another, a light grey colour indicates the risk 
buffered while a dark grey colour indicates where the risk is buffered to. Figure 7 shows that a risk has been buffered from A (Rendering task) to B (Interior doors) and this is recognised from the colours (light grey for A, and dark grey for B) on the tasks. Furthermore, through these various risk statuses for risk response, a virtual visual understanding of a construction project can assist project planners to adjust the scope of the project schedule or even the project design so that likely risks can be avoided, reduced, transferred or exploited for effective risk management and project delivery. As the risks are carefully monitored, it can further provide alerting information if there would be the need to adopt a different risk response measure.

\subsubsection{Risk monitoring}

Nieto-Morote and Ruz-Vila (2011) argued that risk monitoring and control involves implementing a risk response plan, tracking identified risk, monitoring residual risks, identifying new risks, and implementing the risk process effectiveness throughout the project. Synchro allows for the monitoring of scheduled tasks once the tasks have started, thereby providing an insight into the progress of the project schedule against the planned schedule. With monitoring, the planned and actual start dates for task as well as the planned, estimated and actual finish dates for tasks are recorded. Planned date is the date scheduled or arranged for a task to either start or finish while actual date is the true date a particular task is started or finished. The estimated date is attributed to the finish date of a task only and is the date a particular task is judged or approximated to be completed i.e. finished after it has started (see Figure 8). 


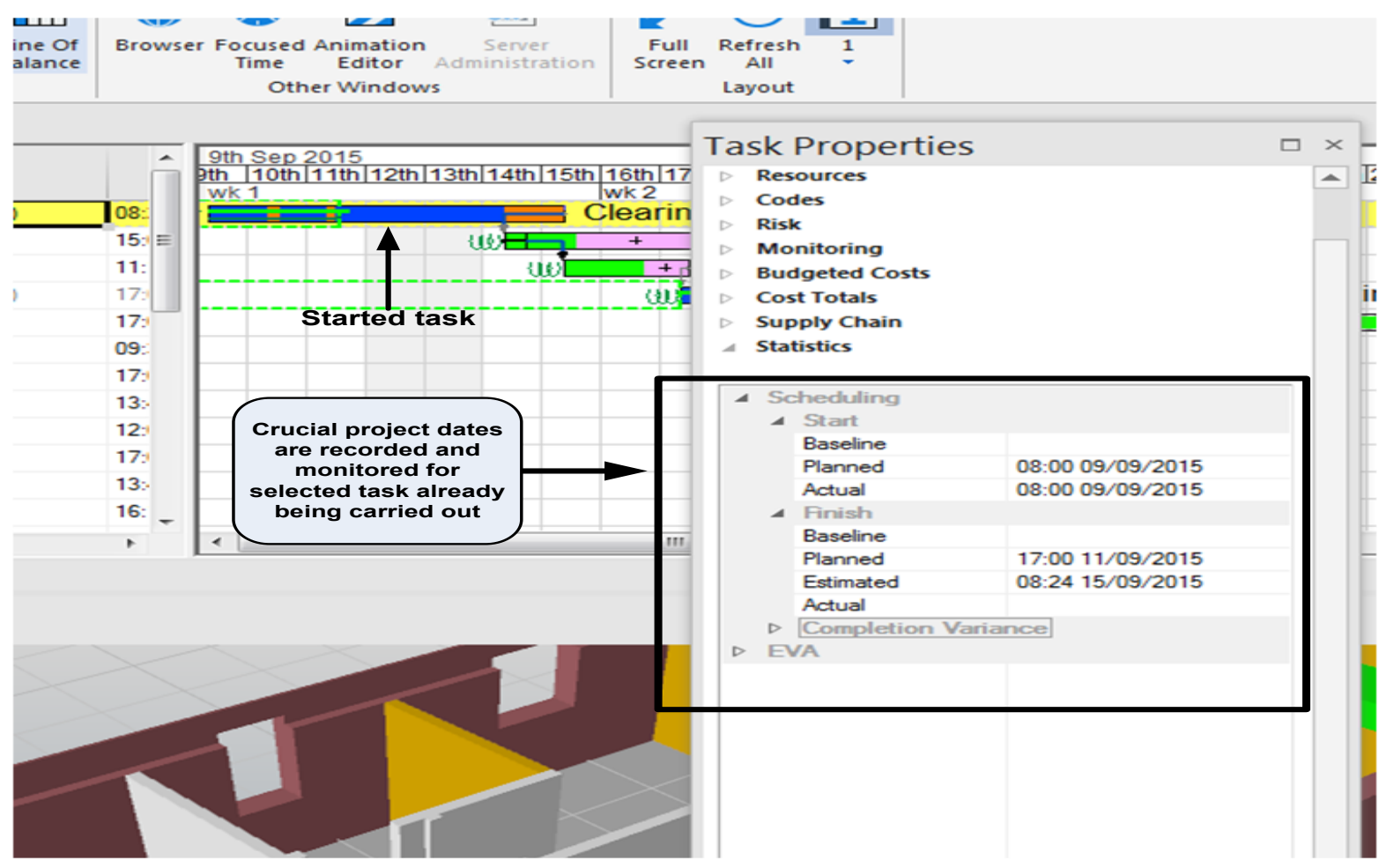

Figure 8 Project dates for a selected task

Monitoring gives information about the percentage of tasks that have been completed as well as the duration remaining for the task(s) to be completed. As such, through monitoring, the progress of tasks can be tracked and reviewed. Figure 9 shows the schedule progress of a task in progress. 


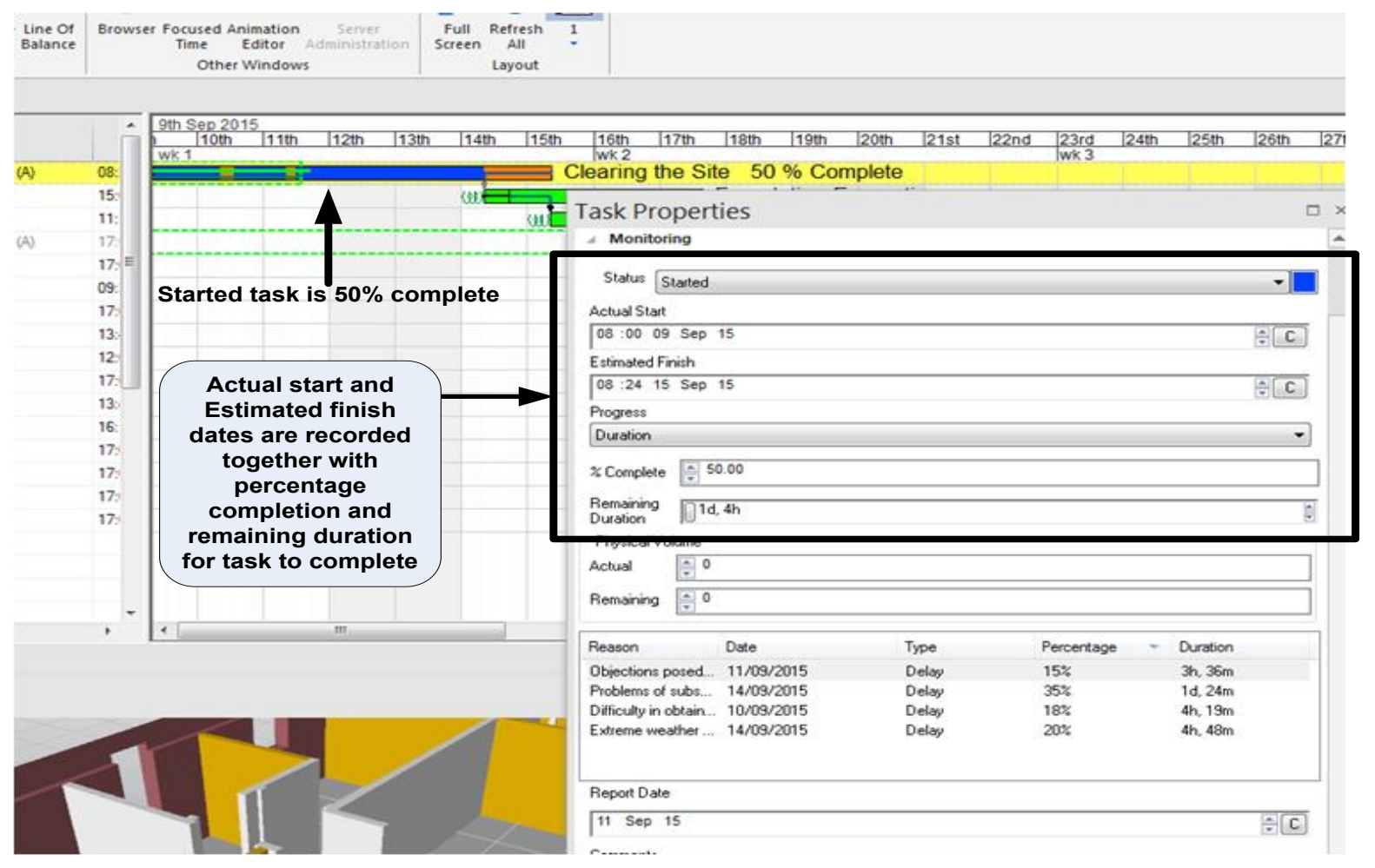

Figure 9 Schedule progress of a started task

From Figure 9, it can be seen that the progress of a task that has already begun can be tracked and monitored. Therefore, any deviation from the project schedule can be accounted for. This is also the same for the report generated by Synchro as a result of the effect of the incurred risks on tasks. Such reports give information about risks causing delay, date of emergence of the various risks and the duration of delay caused. Additionally, it indicates if a project is progressing ahead of schedule. Additional comments to further elicit information about a particular risk or risks incurred can be done in Synchro. This is an aspect that can enhance proper risk communication amongst the project management team. This is illustrated by Figure 10 . 


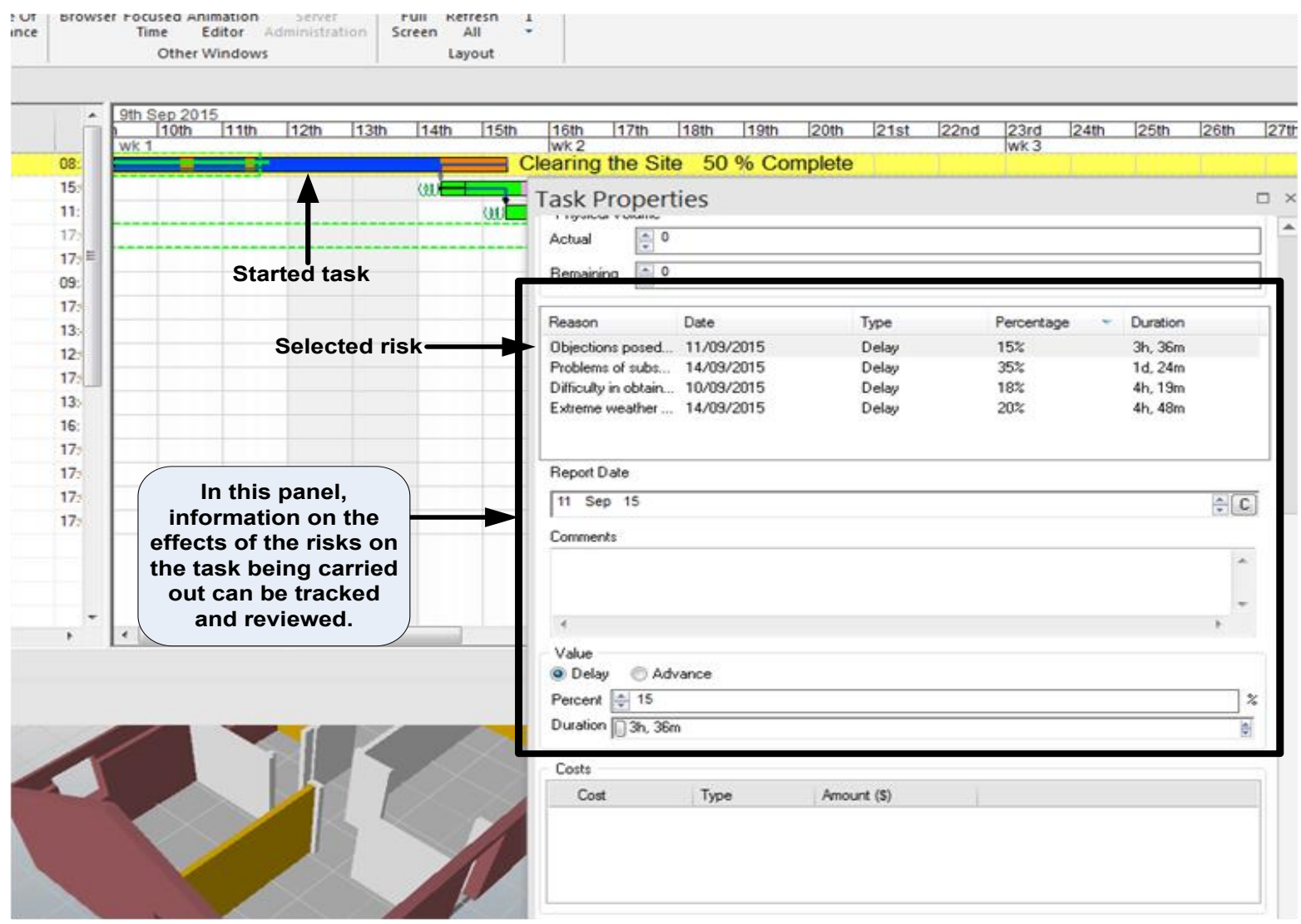

Figure 10 Generated risk report for started task

From Figure 10, it can be seen that a risk report is generated on the various risks associated to the started task. This report provides information on the risks' effect on the project (whether delay or advance) and the percentage effect on the duration of that task. By subsequently selecting any of the risks, it allows for further provision of information through additional comments which can be kept as record of the risk.

Through monitoring, tasks that have risks not assigned to them but have been noticed to be affected by such risks, can be made to incur such risks. The new risks found to be affecting a particular task or tasks can then be fully analysed and recorded. Through this means, construction projects can be tracked all the way to completion while taking note of critical events that can lead to the project running behind schedule. It is of great importance to always revise the programme of works as it is an iterative process rather than a one off process to see if the project is progressing as planned. If otherwise, it might be necessary to examine if tasks are affected by unassigned risks again so that 
measures can be taken to respond to such risks. Through good and effective implementation of risk monitoring, construction projects can be guided to completion as scheduled.

\subsubsection{Risk Communication}

It is well worth noting that project communications management is one of the ten knowledge areas of project management, as such it is paramount to adopt good and effective risk communication for proper risk management. With today's increasing digitization, there is no doubt that there has been a major upsurge in terms of Information and Communications Technology (ICT) globally. BIM together with the internet for project management have provided a more efficient and collaborative platform for parties involved in a project for integrated project delivery. Integrated Project Delivery (IPD) involves highly collaborative processes throughout the lifecycle of a project from the earliest stages, where critical decisions are made and understood to completion, thereby increasing the chances of success (Autodesk, 2008). Risk communication is not undertaken directly in Synchro but can be done using a wider Common Data Environment (CDE), where all BIM models and data are managed. Also, through $\mathrm{CDE}$, information regarding risks can be efficiently and effectively communicated by sharing, publishing and archiving (BIMaaS, 2015). As seen through this study, information generated as well as reviewed in Synchro is highly important for project delivery. Therefore for risks to be effectively managed there is the need to communicate such information to the project team. Based on the preceding steps, a Synchro BIM-based risk management process is presented in Figure 11 using BPMN. 


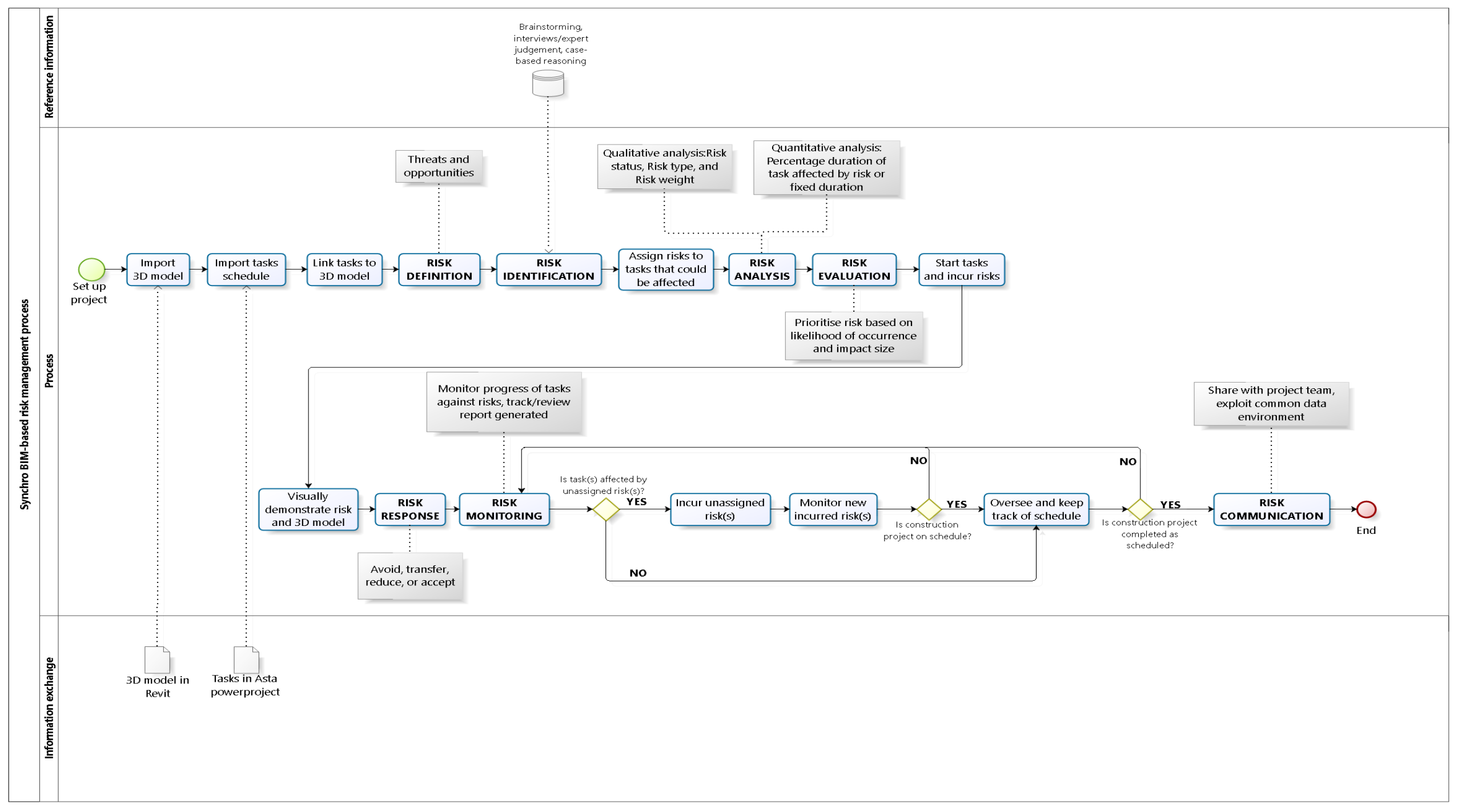

Figure 11 A Synchro BIM-assisted framework for risk management 


\section{The proposed BIM risk management: A Vico-based approach}

Vico office has an integrated approach towards risk management where project managers can better make informed decisions towards optimising project delivery. Similar to the conventional risk management procedures as widely accepted in project management, Vico does not fall short of the fundamentals upon which risk management is built. The following sections discuss the risk management aspect of Vico office. Before the risk management process began, the case study building model was published (exported) from Revit to Vico office. This can be done using the Revit (.rvt) or the IFC file formats.

\subsection{Risk definitions}

Vico office uses Monte Carlo simulation for risk analysis which is a technique that assesses risk in order to evaluate uncertainties (Huang and Wang, 2009). This analysis is executed for five (5) risk categories which Vico office recognises as having the potential to affect the project schedule. These risks include the following:

- $\quad$ Start of schedule risk: This category of risk is based on events that result in delays which may cause project works to commence late. Therefore, this risk is associated with the probability of project works starting on time, as scheduled by the project team to kick-start the project.

- $\quad$ Schedule task duration risk: This category of risk looks at the variable possibilities of workers being able to accomplish a task faster or slower than what is planned. This is calculated in percentages of the already defined duration for that particular task by Vico office.

- $\quad$ Crew/resource come-back delay: This risk assesses the delay (in hours) that could be incurred before workers return to continue or finish a particular task on site after being interrupted. This is because when workers are forced to demobilize from work, it could take a considerable amount of time trying to mobilize them and get them back to continue that task. Therefore, this risk measures the variability associated with mobilizing that same crew to come back to work. 
- Crew/resource beginning delay: Tasks in construction projects are carried out sequentially, and in complex projects, these works are carried out in different locations. When lags are defined for project tasks, workers might have to wait for some days before beginning task in another location. As such, it might take a considerable amount of time to get them to begin such task. This risk examines the delay of getting the crew to begin that particular task.

- Production factor risk: This class of risk evaluates the inconsistencies that could be associated to the defined production factor for a particular task. Simply, this tries to give an assessment of the level of expertise of the trades responsible for executing a particular task.

The analysis of these risk categories by the Monte Carlo Simulation is based on optimistic, most likely, and pessimistic probabilistic scenarios. Based on external or internal risk factors identified that could potentially affect a project, their effect on the project schedule will fall in any of the defined risk categories. Information on the risk(s) arising will then enable project team members to be able to analyse the effects of such risks.

\subsection{Risk identification}

Identifying the various risks that could have an effect on a particular project involves various techniques which are not limited to brainstorming, interview/expert judgement and checklists as illustrated in section 4. The use of such techniques is similar in this case, however, unlike Synchro, Vico office does not provide for the direct attachment of these identified risks to the project tasks, and the ultimate generation of a risk register. Here, an examination of the effects of the identified risks will have to be done externally so as to understand the manner in which they can affect a particular task. This is quite crucial so as to elicit information and make informed decisions on the suitable categories of risks in Vico office that such identified and examined risk(s) will fall into, depending on how they will bring about delay to the project schedule. The risk register in this case will have to be prepared and managed on another platform from which information on the risks can then be incorporated into Vico office. 


\subsection{Risk analysis}

Similar to the conventional risk analysis method as well as the way risk analysis is done in Synchro, analysing project schedule delay risk in Vico can be done qualitatively and quantitatively. Based on the categories of risks, different risk levels defined both in quantitative and qualitative terms are assigned to the scheduled tasks. For quantitative analysis, risk level values of optimistic, most likely, and pessimistic probabilistic scenarios are allocated to different intensities of risks. It is these intensities of risks that are then assigned to tasks for the risk simulation. In the case of the qualitative risk analysis, this involves the description of the chances of occurrence (likelihood) defined for the categories of risks assigned to the project schedule. These chances of occurrence include high (a great chance of occurrence) intermediate (50/50 likelihood), low (slim chance of occurrence), and zero (no chance of occurrence). Figure 12 illustrates the analysis for the project tasks.

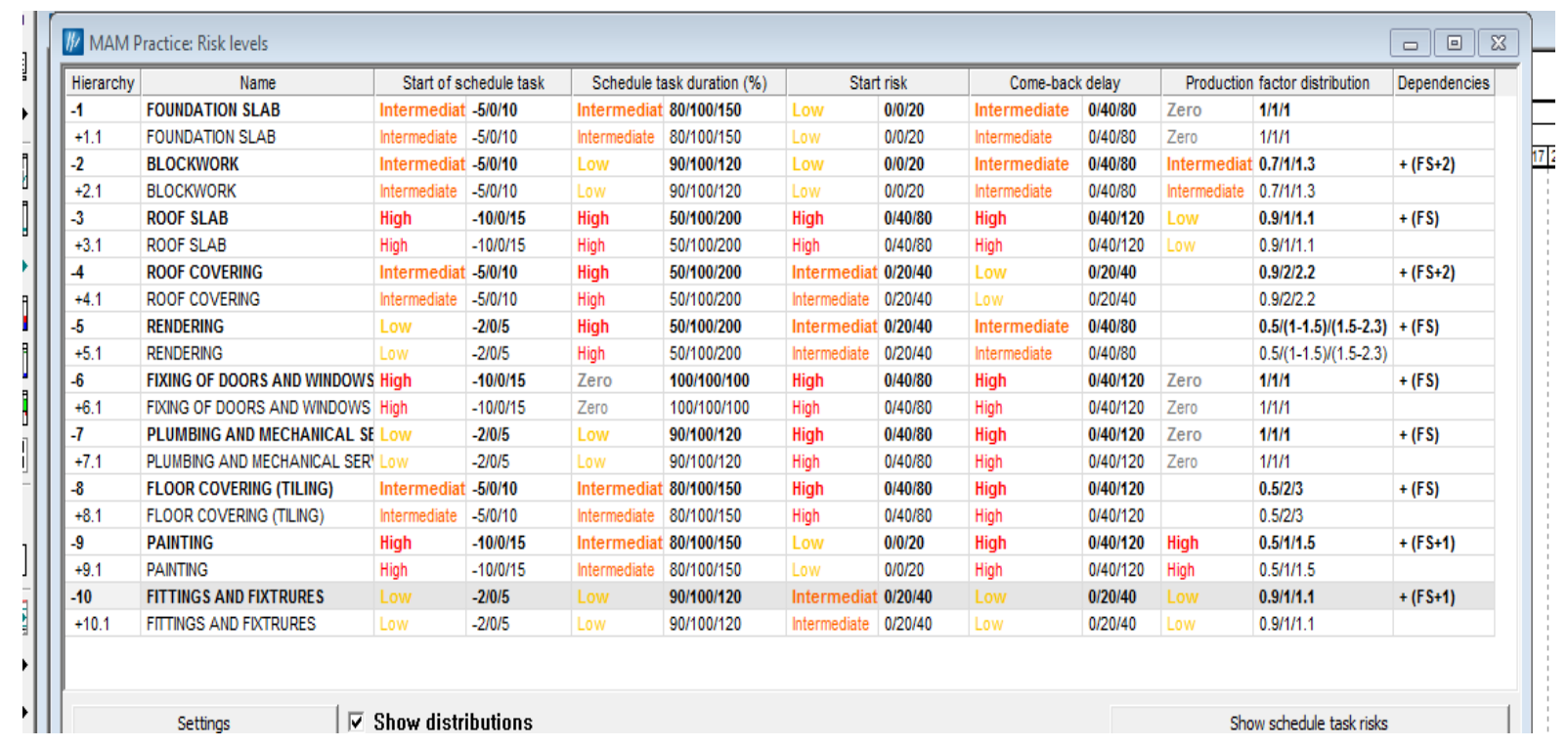

Figure 12 Probabilistic values and likelihood of risks for project tasks

After careful analysis of the likelihood of occurrence and potential impact of risks, to have an understanding of the behaviour of the project as a result of the levels of risks, Monte Carlo simulation was run. This is so as to have an insight on the effects of the risks on the entire project schedule. Monte Carlo simulation is an advantageous mathematical method for the analysis of uncertain scenarios which provides probabilistic analysis of various conditions being monitored (Raychaudhuri, 
2008). According to Huang and Wang (2009), it is an integrated tool which is put to use in order to attain project goals by investigating a variety of uncertainties concurrently. Through Monte Carlo simulation, project teams can be able to understand the impact of uncertainties on construction projects. In this simulation, a random value is selected for the various tasks based on the range of estimates defined for the tasks. Based on this random value, the building model is simulated in order to provide a forecasted result. Thus, the result for this single value is recorded, and the entire process is repeated for another random value. This simulation is carried out hundreds or thousands of times depending on the number of times stipulated for the simulation. In this study, the number of iterations set for this simulation was a thousand (1000) times. Upon completion, the process presented a result for minimum, expected, and maximum duration for the accomplishment of the project. Based on the result, better evaluations can be made in order to manage the impacts of the likely risks that can transpire. Figure 13 illustrates the temporal distribution result for the simulation in this study.

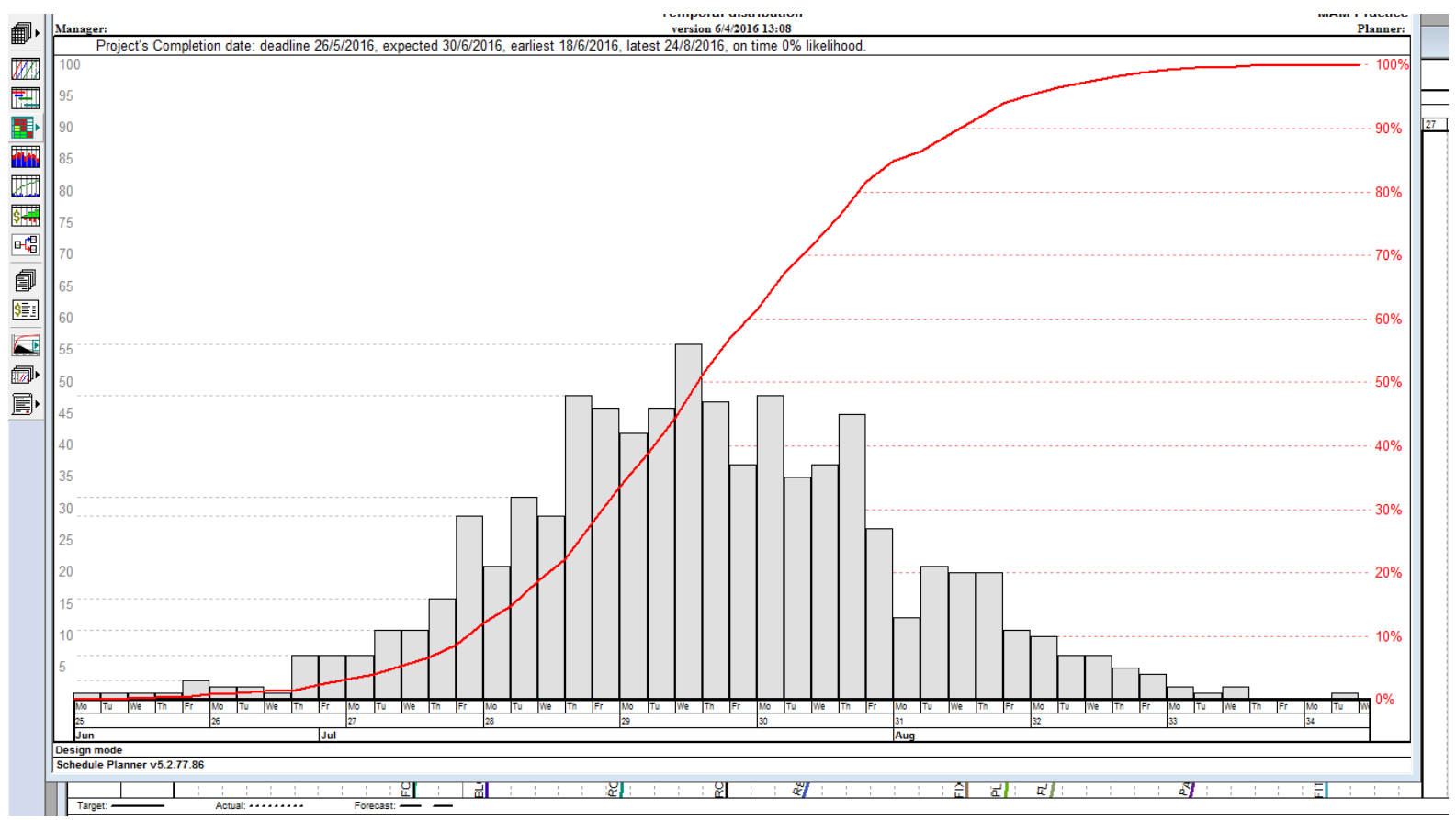

Figure 13 Temporal distribution of Monte Carlo simulation

Based on the results of the simulation, it was seen that there is no chance of the construction project being completed by the deadline date. The deadline of the project is the $26^{\text {th }}$ May, 2016, however the expected (most likely) time of completion is $30^{\text {th }}$ June 2016 , and the earliest time of completion is $18^{\text {th }}$ 
June 2016. The latest possible time of completion is calculated as $24^{\text {th }}$ August, 2016. The results show that there is 35 days difference between the deadline and the most likely time of completion, and 22 days between the deadline and the optimistic (earliest) time of completion. In this case, it is crucial to introduce measures in order to meet the earliest possible time of completion. In the project schedule flowline view, further information is given on the effects of the risks on the project tasks. Figure 14 shows the criticality or impact of the risks on tasks.

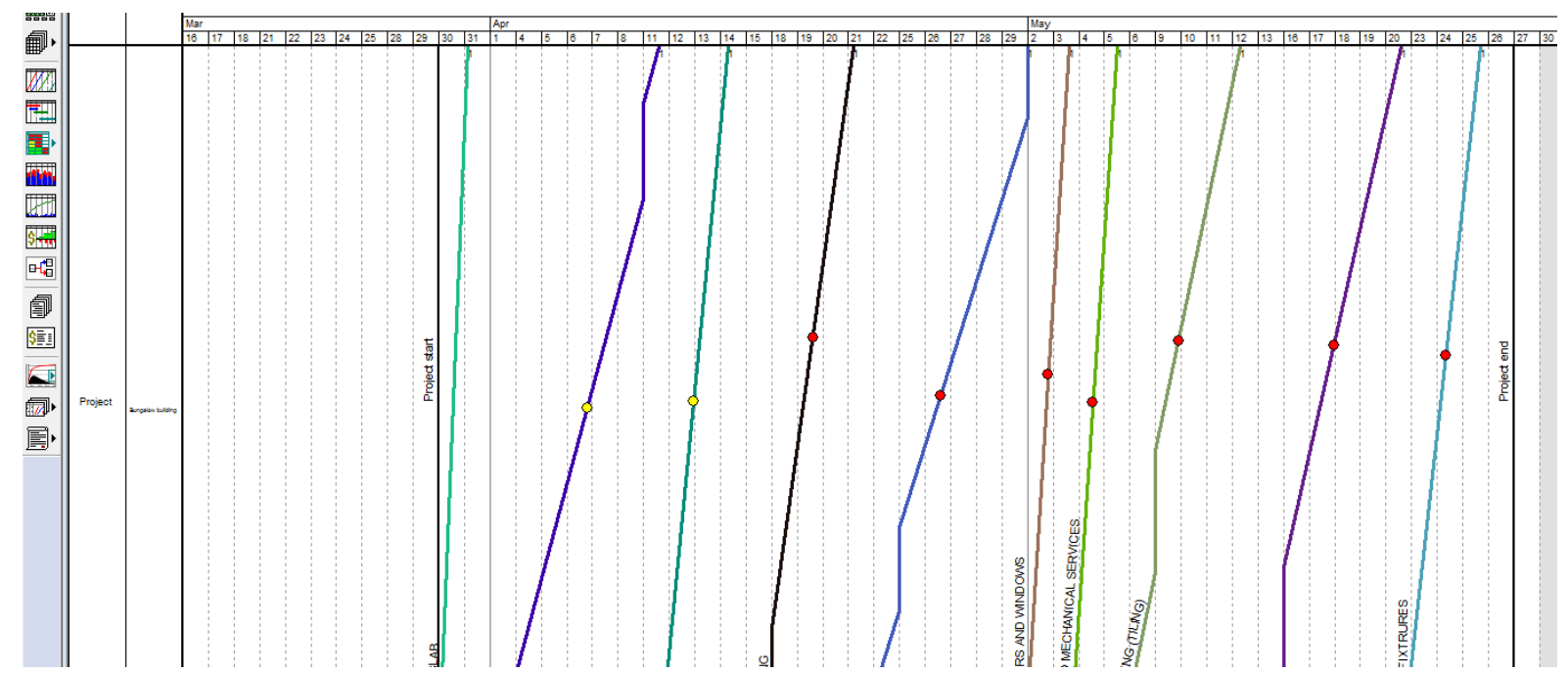

Figure 14 Risk effects on tasks

Intensities (or impacts) of risks on project tasks are denoted by coloured nodes. Green nodes indicate no (or very minimal) impact of risks on tasks, whereas yellow and red nodes indicate lesser and higher impacts of the risks on project tasks respectively. In this case, it can be noted that a huge number of tasks for this project are affected by higher impacts of risks; hence there is the need to fashion out ways of mitigating such risks in order to attain an earlier completion date.

\subsection{Risk evaluation}

As discussed earlier, the aim of risk evaluation is to prioritise risks based on their importance. This means that risks that could potentially have a great impact on project tasks will have to be noted in order to decide on the best possible measures to tackle such risks. Based on the results of the Monte Carlo simulation, Figure 14 indicates that seven tasks have the potential to be greatly affected by the defined risks assigned to the tasks. This means that more resources or measures should be channelled 
to these tasks in order to mitigate the risks that could affect these tasks. Figure 15 indicates the critical tasks that need more attention in order to mitigate the potential risks on them.

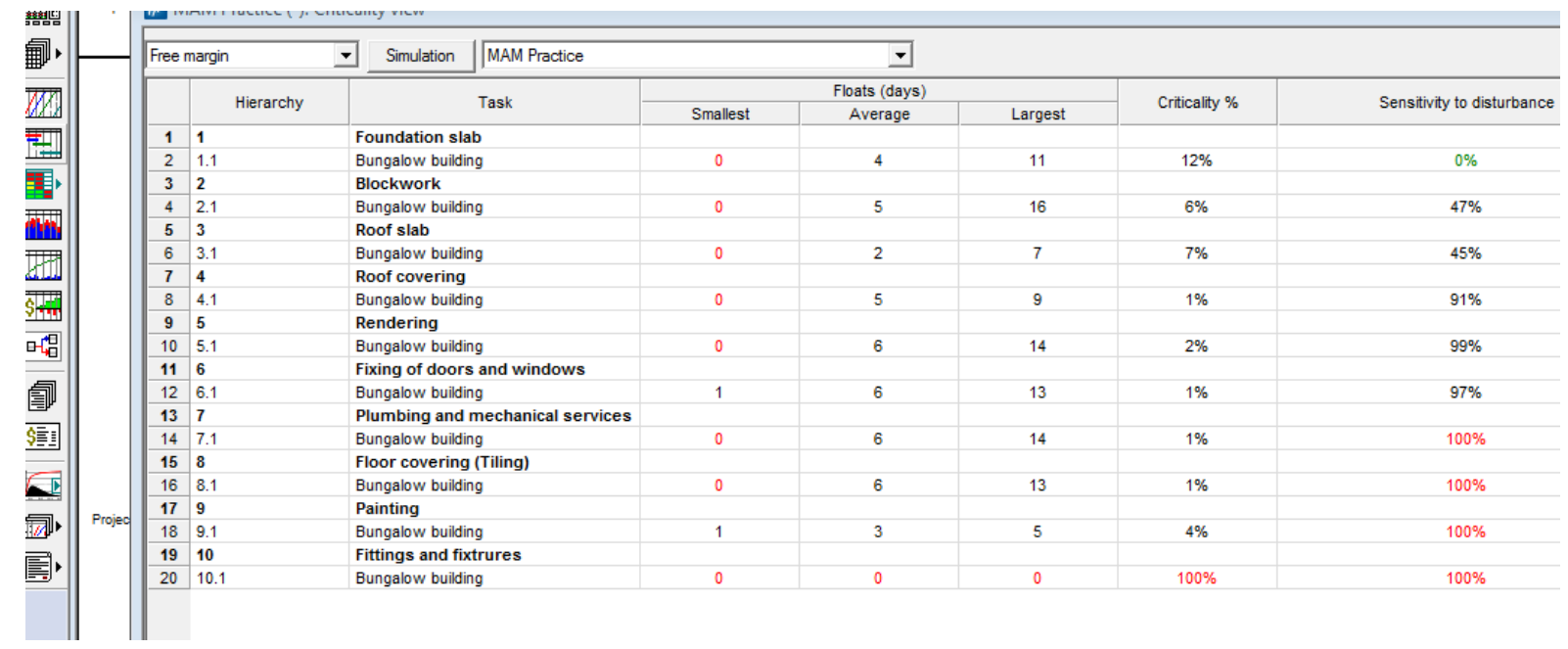

Figure 15 Sensitivity of tasks to risks

Based on the results obtained from Figure 15, the tasks of plumbing and mechanical services, floor covering, painting, as well as fittings and fixtures happen to have the highest sensitivity of risks. In this case, these tasks need to be prioritised more than the rest in other to ensure better risk management.

\subsection{Risk response}

Adding buffers in a project schedule for tasks is a way of mitigating risks that could affect a project schedule. A buffer is an extra time (specifically shift length) which is added to the durations of individual tasks to neutralize the effects of uncertainties and protect against variations in work progress (Russel et al., 2013). Simply, a buffer serves as a way of optimising a project schedule with the aim of ensuring continuous flow of works without interruption and absorbing or mitigating the impact of risks on a construction project. Furthermore, Vico office allows for the splitting of tasks if necessary to ensure that a crew can be split to work at different independent locations on the same project (especially with complex projects). This allows for establishing an efficient project schedule where tasks can be completed on time. Additionally, project locations have a dependency where one location must be finished before another, tasks on a depending location can be set to commence as 
soon as it is possible to start such tasks at such locations. This is so that the project schedule will have a continuous flow of works without any start and stops in the project schedule that can ultimately affect the project time schedule. Another way of tackling risks in Vico office is by increasing the number of resources assigned to tasks which is the number of workers assigned to a particular task or a number of tasks. By so doing, the production rate is increased for such tasks thereby protecting such tasks from the impact of risks on the project schedule. In the case of this study, project buffers were added to the tasks where the effects of risks are quite great. Figure 16 shows the results of the simulation after buffers were added to the tasks to counter the effect of potential risks.

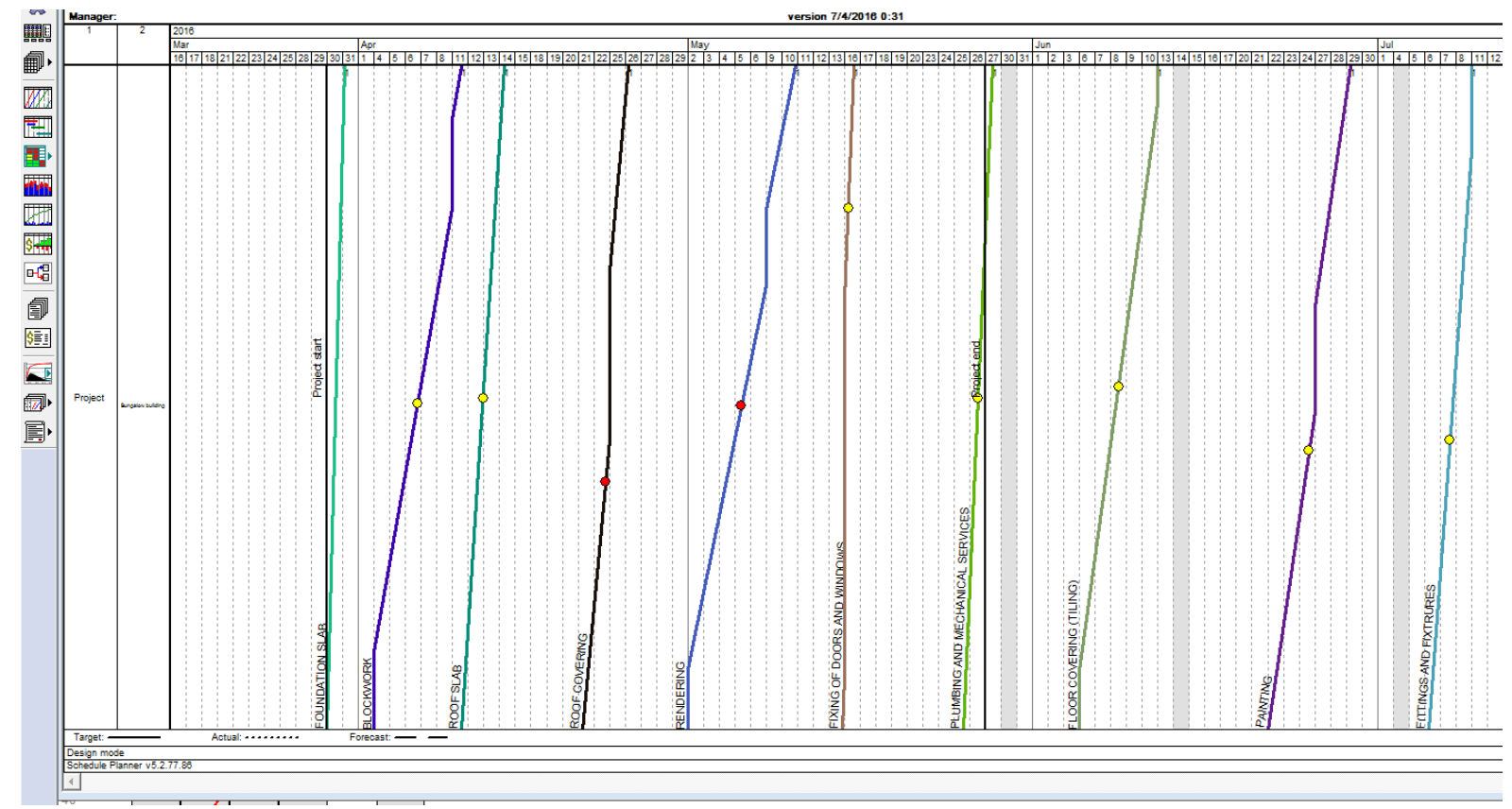

Figure 16: Risk mitigation by adding buffers to tasks

From Figure 16, buffers were added to the project tasks in order to mitigate potential risks. Initially, plumbing and mechanical services, floor covering, painting, as well as fittings and fixtures had the highest risk impacts. However, after adding buffers of eight, six, seven and four days respectively, the impact of risk became very much less on these tasks as denoted by the yellow nodes. Figures 17 and 18 illustrate the temporal distribution of the Monte Carlo simulation and sensitivity of the tasks to the risks respectively. 


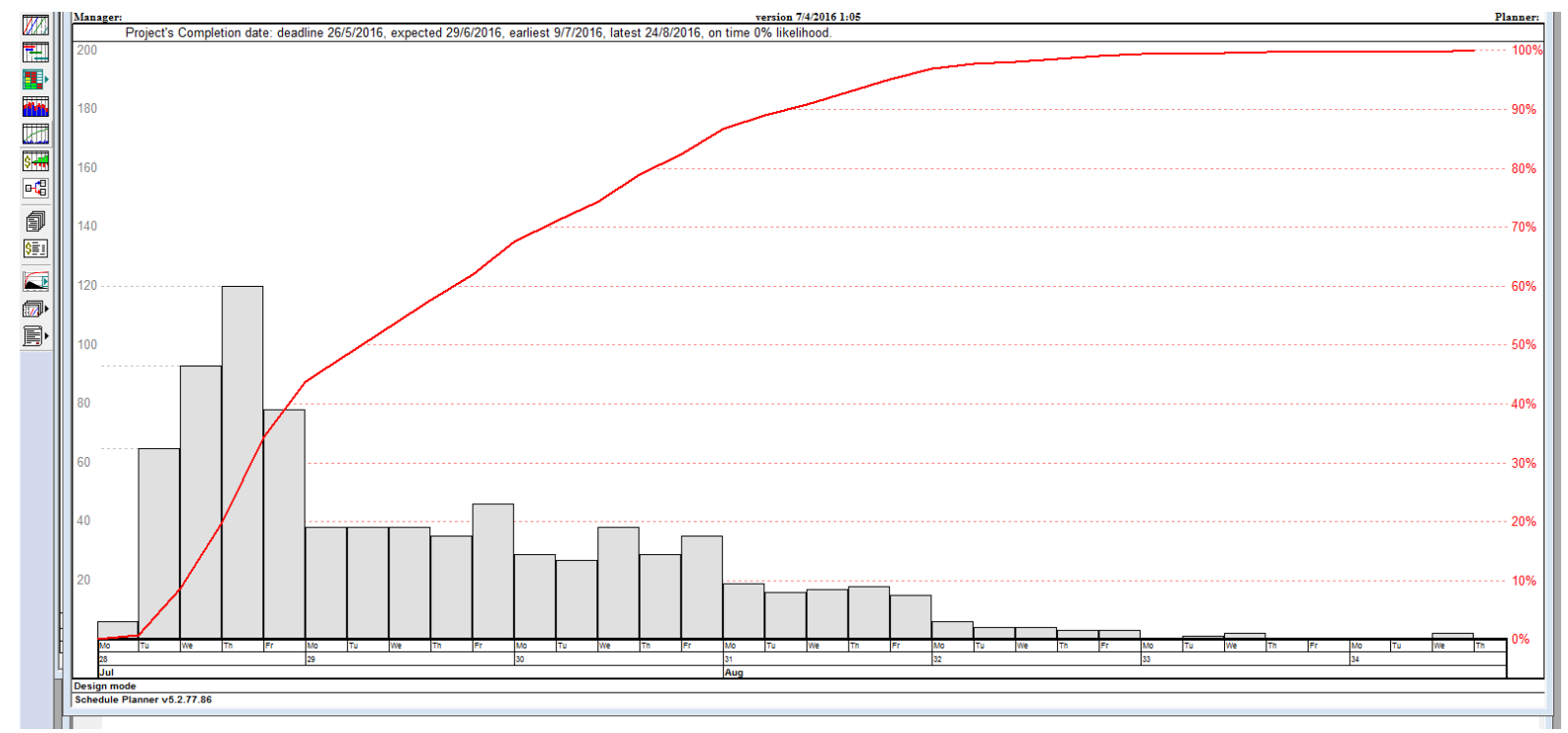

Figure 17 Temporal distribution of Monte Carlo simulation

\begin{tabular}{|c|c|c|c|c|c|c|c|c|}
\hline \multicolumn{2}{|c|}{ Free margin } & \multirow{3}{*}{$\nabla$} & \multirow{3}{*}{ Simulation } & \multicolumn{3}{|c|}{$\nabla$} & \multirow{3}{*}{ Criticality \% } & \multirow{3}{*}{ Sensitivity to disturbance } \\
\hline & \multirow{2}{*}{ Hierarchy } & & & & Floats (days & & & \\
\hline & & & & Smallest & Average & Largest & & \\
\hline 1 & 1 & \multicolumn{2}{|r|}{ Foundation slab } & & & & & \\
\hline 2 & 1.1 & \multicolumn{2}{|r|}{ Bungalow building } & 0 & 4 & 10 & $13 \%$ & $0 \%$ \\
\hline 3 & 2 & & \multirow{2}{*}{ Blockwork } & & & & & \\
\hline 4 & 2.1 & & & 0 & 5 & 17 & $6 \%$ & $48 \%$ \\
\hline 5 & 3 & \multicolumn{2}{|r|}{ Roof slab } & & & & & \\
\hline 6 & 3.1 & \multicolumn{2}{|r|}{ Bungalow building } & 0 & 3 & 12 & $9 \%$ & $42 \%$ \\
\hline 7 & 4 & \multicolumn{2}{|r|}{ Roof covering } & & & & & \\
\hline 8 & 4.1 & \multirow{2}{*}{\multicolumn{2}{|c|}{$\begin{array}{l}\text { Bungalow building } \\
\text { Rendering }\end{array}$}} & 0 & 4 & 10 & $7 \%$ & $70 \%$ \\
\hline 9 & 5 & & & & & & & \\
\hline 10 & 5.1 & \multicolumn{2}{|r|}{ Bungalow building } & 0 & 6 & 21 & $6 \%$ & $71 \%$ \\
\hline 11 & 6 & \multicolumn{2}{|r|}{ Fixing of doors and windows } & & & & & \\
\hline 12 & 6.1 & \multirow{2}{*}{\multicolumn{2}{|c|}{$\begin{array}{l}\text { Bungalow building } \\
\text { Plumbing and mechanical services }\end{array}$}} & 0 & 6 & 20 & $6 \%$ & $61 \%$ \\
\hline 13 & 7 & & & & & & & \\
\hline 14 & 7.1 & \multicolumn{2}{|r|}{ Bungalow building } & 0 & 6 & 18 & $5 \%$ & $51 \%$ \\
\hline 15 & 8 & & Floor covering (Tiling) & & & & & \\
\hline 16 & 8.1 & \multirow{2}{*}{\multicolumn{2}{|c|}{$\begin{array}{l}\text { Bungalow building } \\
\text { Painting }\end{array}$}} & 0 & 5 & 16 & $5 \%$ & $43 \%$ \\
\hline 17 & 9 & & & & & & & \\
\hline 18 & 9.1 & \multicolumn{2}{|r|}{ Bungalow building } & 0 & 3 & 12 & $8 \%$ & $65 \%$ \\
\hline 19 & 10 & \multicolumn{2}{|r|}{ Fittings and fixtrures } & & & & & \\
\hline 20 & 10.1 & \multicolumn{2}{|r|}{ Bungalow building } & 0 & 0 & 0 & $100 \%$ & $62 \%$ \\
\hline
\end{tabular}

Figure 18 Sensitivity of tasks to risks

From Figure 17, buffers do not increase the project time schedule, but rather, they neutralise the effect of risks in a project. The temporal distribution result does not show significant changes in terms of the project timeframe. The expected (most likely time) of completion stands at $29^{\text {th }}$ June, 2016, which is a day earlier than the previous simulation $\left(30^{\text {th }}\right.$ June, 2016$)$ whereas the latest possible completion time still stands at $24^{\text {th }}$ August, 2016. On the other hand, Figure 18 illustrates a much less sensitivity of the tasks to the project risks compared to Figure 15 where plumbing and mechanical services, floor covering, painting together with fittings and fixtures had very high sensitivity to risks. Based on these 
results, it can be noted that there is no significant changes to the project schedule in order to bring it closer to the deadline. However, what is more important is the fact that adequate measures can be taken in order to manage potential risks which, if not managed properly, can further cause the project to go well beyond schedule. As such, this can further bring about cost overruns making the project go well above budget.

\subsection{Risk monitoring}

All construction projects, especially complex projects, are not risk free because as primary risks are mitigated, secondary risks arise which should be taken into account together with the residual risks that could still be inherent in any project. In this study, after adding buffers in order to respond to the risks, the impact of the risks on the tasks were controlled (mitigated), but not fully eliminated. This is indicated by the yellow nodes in Figure 16 denoting that the risks in the tasks are less risky compared to the red nodes in Figure 14 which indicated that the tasks are subjected to highly risky events. It is then paramount that these tasks in Figure 16 are carefully monitored to ensure better risk management making sure that the residual risks do not further cause the project schedule to fall out of place. As new risks surface, the risk levels for tasks can be reviewed, and another simulation Monte Carlo simulation can be carried out to understand the effect of the risks on tasks and consequently on the project schedule. By so doing, necessary measures can be taken to respond to such risks. With Vico office, tasks more susceptible to great impacts of risks can be tracked and monitored once works commence to ensure that risks inherent in them can be properly managed.

\subsection{Risk communication}

Risk communication is quite an important part of the whole risk management process; therefore it is imperative that project teams are well informed of the risks that a construction project is exposed to. Vico office allows for the sharing of information among project teams through the Vico project server. Here, information can be stored and shared through a network of database especially for well established companies. However, for better collaboration, highly collaborative processes such as Integrated Project Delivery (IPD) and Common Data Environment (CDE) can enable better risk 
management. This will guarantee the needed documentation to ensure that everyone associated to a project gets a hassle free access to information as and when required. Based on the preceding steps, a Vico BIM-based risk management process is presented in Figure 19 using BPMN. 


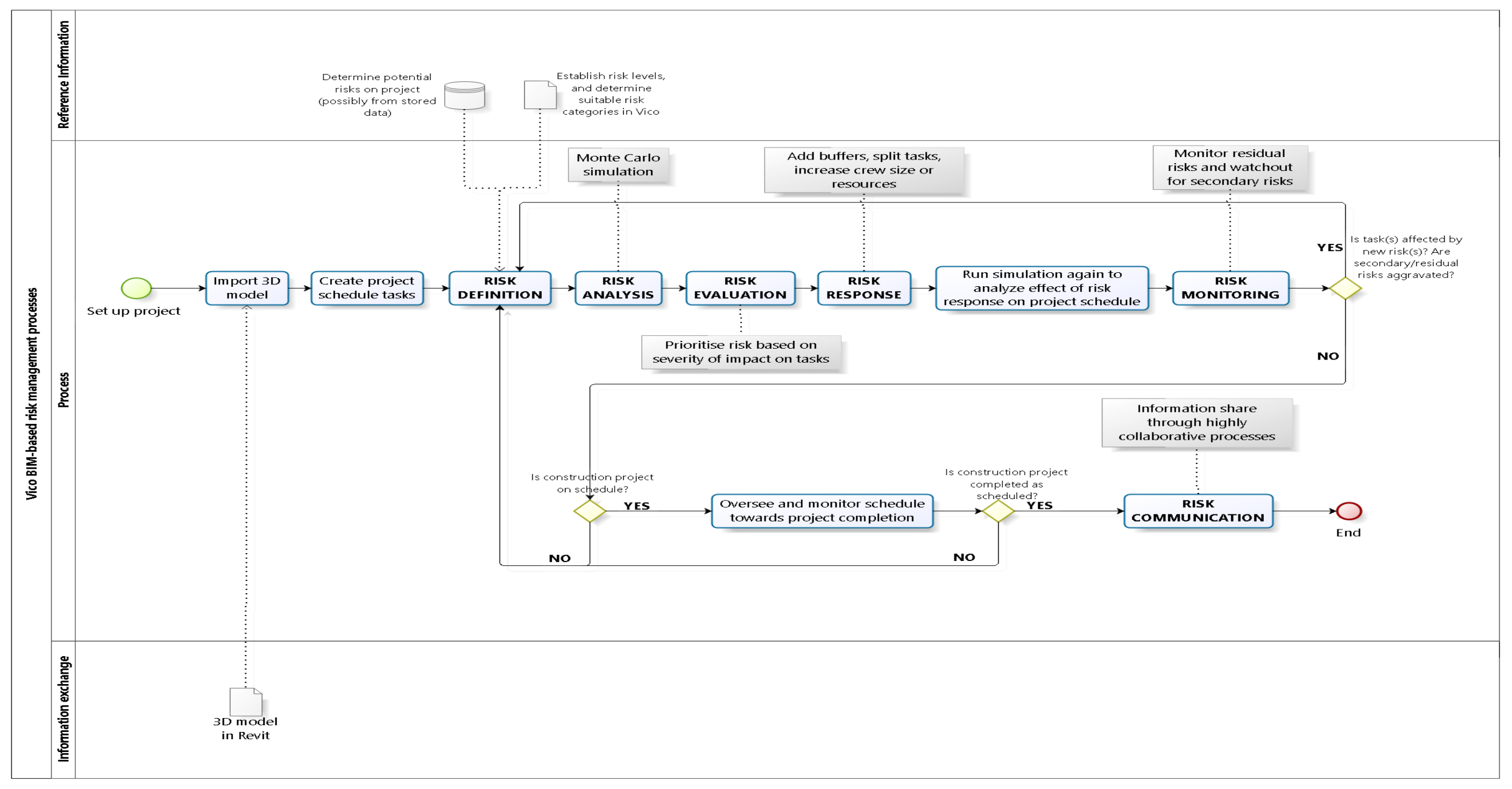

Figure 19 Vico BIM-based risk management process model 


\section{Generalisation of methods}

Quite often, case study research is criticised based on the fact that its findings are not universal when compared to those of survey research (Gomm et al., 2000). However, the aim is to provide a sound understanding of the situation through an intensive study of particular cases (Polit and Beck, 2010). On this premise, we were able to generate broader conclusions as a result of the steps pursued in the development of risk management frameworks beyond the case study software. Generating concepts beyond a case is what Oates (2006) called "generalisation" in the context of case study research. Based on the developed Synchro- and Vico-based, a combined framework of BIM-based risk management process is presented in Figure 20. 


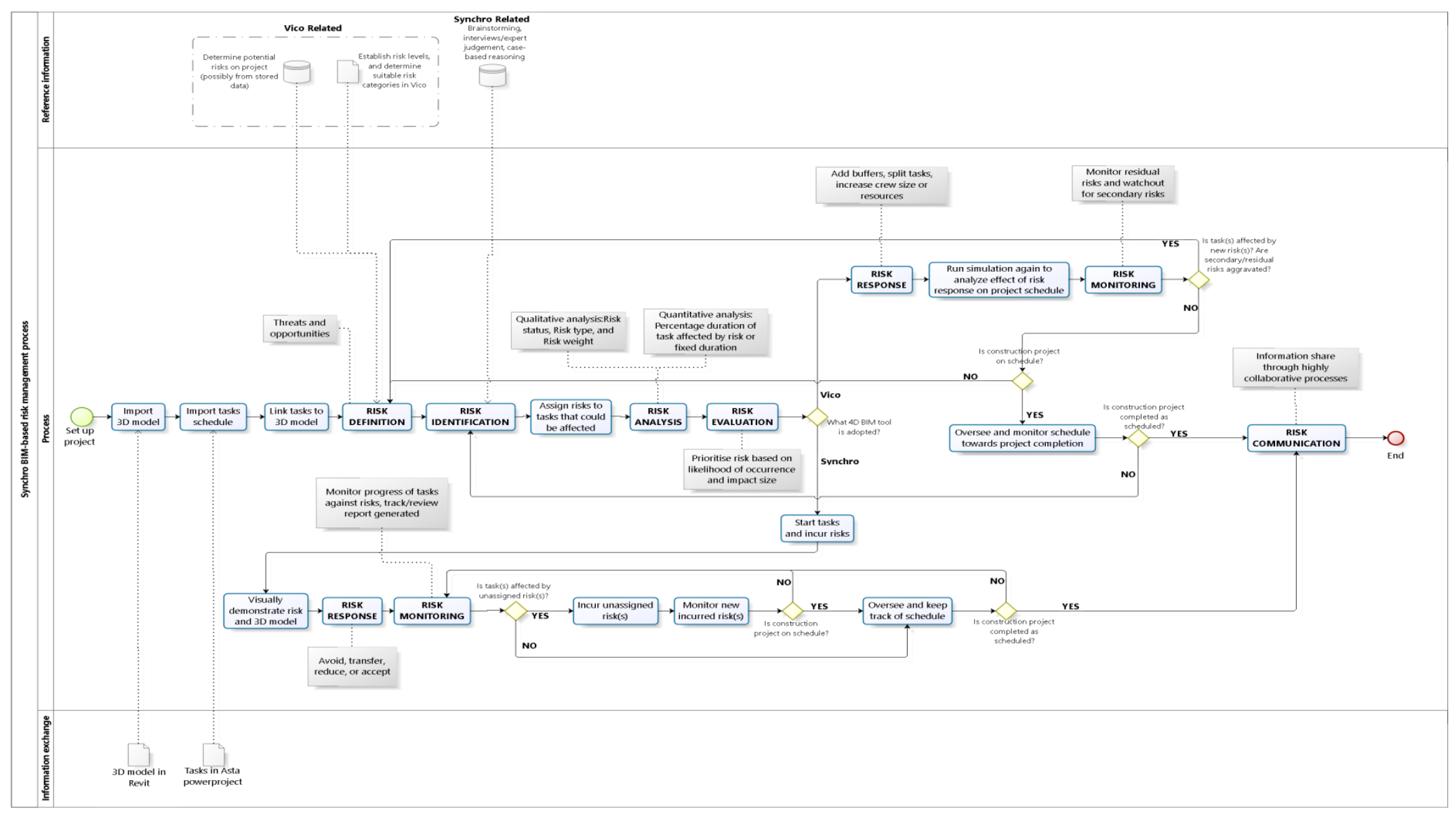

Figure 20: A generalised BIM-based risk management process model 
From the start-up of the project to the first gateway, risk activities are similar in the way they are executed in Synchro and Vico. After the gateway, the activities that are specific to Vico or Synchro are illustrated. This framework offers opportunities to embed other activities depending on the type of software used if significantly different from the Synchro- and Vico-based type risk management activities. This can be achieved by using gateways that offers branches to switch to different types of software related risk management activities.

\section{Validation of frameworks}

The frameworks were validated for their syntactic and semantic correctness. Syntactically, Bizagi was used in parsing through the components and their connections in the frameworks. Errors were identified and corrected through iterations until a final correct product was obtained. The second semantic validation task consists of establishing whether the framework produced can be employed in managing risk in other 4D/5D BIM environments. To this effect, three experts with expert knowledge of Synchro and Vico were chosen to test the framework. Two of experts were very proficient in Synchro and one was proficient in Vico, with each one of them having at least five years of experience in the use of Synchro or Vico. One of the Synchro users was from academia while the other plus the Vico user were construction professionals from the industry. Their initial feedback highlighted some challenges and some missing aspects. As an example, the Communication (similar to others highlighted in dash lines) step was not included as they were thought to be softer issues not directly related with Synchro. However, their suggestions was that such issues should be considered in the wider framework of integrated or collaborative project delivery where project partners can readily share or communicate information using BIM related tools or Common Data Environments. The feedback led to the refinement of the framework until the final usable product was obtained as presented in Figure 20.

\section{Conclusions}

BIM has been hailed as a solution to challenges faced by many professionals in the construction industry. Although there has been a multiplicity of BIM software systems in the market (e.g. see Abanda et al. 2015), their applications have often been on mainstream construction issues such as 
quantity take-offs, cost estimation, scheduling, sustainability, etc. Perhaps one of the reasons for the lack of BIM application for risk management is due to the fact that most 4D BIM systems still lack the risk components as revealed in Table 1. Also, research in this area is scarce with some major studies still ongoing (e.g. Zou et al., 2015). Given the scarcity of literature about the research area, an exploratory approach that employs case study was adopted. Two major BIM software systems, Synchro and Vico were used as case studies in exploring risk management on a dwelling with wellknown information. Building on existing risk management models, the processes of risk management were explored in Synchro and Vico. The process were documented, scrutinised and used to develop an easy-to-follow framework that can be adopted on any building project. Although many studies that use case studies are often criticised for being too focused on the case or cases in question, we believe that the framework proposed can be used with most 4/5D-BIM modelling software systems. This is justified by the fact that the approach developed is based on existing risk management models and developed using two leading 4D BIM (i.e. Synchro) and 5D-BIM (i.e. Vico) software systems. Consequently, we can argue that the framework generated are relevant beyond the case studies and can be used on other nD-BIM modelling software systems. Although there are very few 4/5D-BIM modelling tools as can be seen in Table 1, part of our future study will consists of exploring this framework on other emerging BIM software systems. The challenge to this is the lack of trial versions of most of the software and our success in exploring the proposed future aspects of this study will depend on the goodwill of BIM vendors or manufacturers in providing trial and/or educational versions.

\section{References}

Abanda F.H. and Byers L. (2016) An investigation of the impact of building orientation on energy consumption in a domestic building using emerging BIM (Building Information Modelling). Journal of Energy, Vol. 97, pp. 517-527.

Abanda F.H., Nkeng G.E., Tah J.H.M., Ohandja E.N.F. and Manjia M.B. (2014) Embodied energy and $\mathrm{CO}_{2}$ analyses of mud-brick and cement-block houses. AIMS Energy Journal, Vol. 2 (1), pp.18-40. 
Abanda F.H., Vidalakis C., Oti A.H. and Tah J.H.M. (2015) A critical analysis of Building Information Modelling systems used in construction projects. Advances in Engineering Software, Vol. 90, pp. 183-201.

Ameyaw E.E., Chan A.P.C., Owusu-Manu D.-G. and Coleman E. (2015) A fuzzy model for evaluating risk impacts on variability between contract sum and final account in government-funded construction projects. Journal of Facilities Management, Vol. 13(1), pp. $45-69$.

Araszkiewicz K. (2015) Building Information Modelling: An innovative way to manage risk in construction projects. International Journal of Contemporary Management, Vol. 4(3), pp. 23-40.

Assaf, S. A. and Al-Hejji, S. (2006) Causes of delay in large construction projects. International Journal of Management, Vol. 24(4), pp. 349-357.

Autodesk (2008) Improving building industry results through Integrated Project Delivery and Building Information Modelling [online] http://images.autodesk.com/latin_am_main/files/bim and ipd_whitepaper.pdf (Accessed 15 January 2016).

Baloi, D. (2012) Risk analysis techniques in construction engineering projects. Journal of Risk Analysis and Crisis Response, Vol. 2(2), pp. 115-123.

Banaitiene, N. and Banaitis, A. (2012) Risk management in construction projects. Available at: http://dx.doi.org/10.5772/51460 (Accessed on: 26 May, 2015).

Banaitiene, N., Banaitis, A., and Norkus, A (2011) Risk management in projects: Peculiarities of Lithuanian construction companies. International Journal of Strategic Property Management, Vol. 15(1), pp. 60-73.

BIMaaS (2015) Sophisticated common data environment (CDE) with BIMaaS platform [online] http://www.bimaas.uk/wp-content/uploads/2015/09/Sophisticated-Common-DataEnvironment-CDE-with-BIMaaS-Platform.pdf (Accessed 16 January, 2016).

Bing, L, Akintoye, A, Edwards, P.J. and Hardcastle, C. (2005) The allocation of risk in PPP/PFI construction projects in the UK. International Journal of Project Management, Vol. 23(1), pp. 25-35.

BSI (2013) PAS 1192-2:2013: Specification for information management for the capital/delivery phase of construction projects using building information modelling. The British Standards Institution, UK.

Buehring, S (2012) PRINCE2 theme: Risk [online] http://www.whatisprince2.net/prince2theme-risk.php (Accessed 13 January, 2015). 
Carr V. and Tah J.H.M. (2001) A fuzzy logic approach to construction project risk assessment and analysis: construction project risk management system. Advances in Engineering Software, Vol. 32 (10-11), pp. 847-857.

Chen X.X, Chen R.H., Lin K. and Zhang M.W. (2014) Application of the improved Analytic Hierarchy Process in the risk management of tunnel construction. Applied Mechanics and Materials, Vol. 696, pp. 295-300.

Chen Y.Q., Zhang S.J., Liu L.S. and Hu J. (2015) Risk perception and propensity in bid/nobid decision-making of construction projects. Engineering, Construction and Architectural Management, Vol. 22 (1), pp.2 - 20.

Cooper D.F., MacDonald D.H. and Chapman CB. (1985) Risk analysis of a construction cost estimate. International Journal of Project Management, Vol. 3 (3), pp. 141-149.

d'Albe E.M.F. (1982) An approach to earthquake risk management. Engineering Structures, Vol. 4(3), pp. 147-152.

De Marco A. and Thaheem M.J (2014) Risk analysis in construction projects: a practical selection methodology, American Journal of Applied Sciences, Vol. 11(1), pp. 74-84.

Designing Buildings (2015) Risk in building design and construction, [online] http://www.designingbuildings.co.uk/wiki/Risk_in_building_design_and_construction (accessed 12th January, 2016).

Dooley, K. (2002) Simulation research methods. Companion to Organizations, Joel Baum (ed.), London: Blackwell.

Ehsan, N., Mirza, E., Alam, M., and Ishaque, A. (2010) Risk management in construction industry, Computer Science and Information Technology (ICCSIT), $20103^{\text {rd }}$ IEEE International Conference, Vol. 9, pp. 16-21.

El-Karim, M.S.B.A, El-Nawawy, O.A.M and Abdel-Alim, A.M (2015) Identification and assessment of risk factors affecting construction projects, HBRC Journal, [Online] doi:10.1016/j.hbrcj.2015.05.001 (Accessed 17 January 2016).

Ghazali, F.E.M and Kabir, S (2009) Determination of risk identification process employed by the NHS for a PFI hospital project in the UK, Journal of Industrial Engineering and Management, Vol. 2(3), pp. 558-568.

Gomm, R, Hammersley, M and Foster, P (2000) Case study method: Key issues, key texts, London: Sage.

Hammad D.B., Rishi A.G. and Yahaya M.B. (2015) Mitigating construction project risk using Building Information Modelling (BIM). In: Laryea, S., Agyepong, S.A., Leiringer, R. 
and Hughes, W. (Eds) Procs 4th West Africa Built Environment Research (WABER) Conference, 24-26 July 2012, Abuja, Nigeria, 643-652.

Highways Agency (2013) Annual report and accounts 2012-2013 [online]

https://www.gov.uk/government/uploads/system/uploads/attachment_data/file/246620/035 4.pdf (Accessed 17 January, 2016).

HSE (2010) Improving health and safety: An analysis of HSE's risk communication in the $21^{\text {st }}$ century [online] http://www.hse.gov.uk/research/rrpdf/rr785.pdf (Accessed 16 January 2016).

Hwang B.-G. and Ng. W.J. (2013)Project management knowledge and skills for green construction: Overcoming challenges. International Journal of Project Management, Vol. 31, pp. 272-284.

Huang, J and Wang X (2009) Risk analysis of construction schedule based on PERT and MC simulation. International Conference on Information Management, Innovation Management and Industrial Engineering, pp. 464-473.

Ihrig, M (2012). A new research architecture for the simulation era. In: Lotzmann. $26^{\text {th }}$ European Conference on Modelling and Simulation, 39th May 2012, Germany. Koblenz: ECMS Klaus G.

Jannadi O.A. and Amishari S. (2003) Risk assessment in construction. Journal of Construction Engineering and Management, Vol. 129 (5), pp. 492-500.

Kangari R. and Boyer L.T. (1981) Project selection under risk. Journal of the Construction Division, Vol. 107 (4), pp. 597-608.

Kansal, R. K and Sharma, M (2012) Risk assessment methods and application in the construction projects, International Journal of Modern Engineering Research, Vol. 2(3), pp. 1081-1085.

Khodeir, L.M. and Mohamed, A.H.M. (2015) Identifying the latest risk probabilities affecting construction projects in Egypt according to political and economic variables. From January 2011 to January 2013, HBRC Journal, Vol. 11(1), pp. 129-135.

Kim J.I., Kim J., Fischer M., and Orr R. (2015) BIM-based decision-support for master planning of sustainable large-scale developments (2015). Automation in Construction, Vol (58), pp. 95-108.

Lee S., Kim K. and Yu J. (2014) BIM and ontology-based approach for building cost estimation. Automation in Construction, Vol. (41), pp. 96-105.

Levitt R.E., Logcher R.D. and Ashley D.B. (1980) Allocating risk and incentive in construction. Journal of the Construction Division, Vol. 106(3), pp. 297-305. 
Mahendra, P.A., Pitroda, J.R and Bhavsar, J.J (2013) A study of risk management techniques for construction projects in developing countries. International Journal of Innovative Technology and Exploring Engineering (IJITEE), Vol. 3(5), pp. 139-142.

Malekitabar H., Ardeshir A., Sebt M.H. and Stouffs R. (2016) Construction risk drivers: A BIM approach, Safety Science, Vol. 82, pp. 445-455.

Malvar M.J.S and Likhitruangsilp V. (2014) A framework of designating appropriate Building Information Modeling (BIM) uses for managing Design and Build project risks. The TwentySeventh KKHTCNN Symposium on Civil Engineering, November 9-12, 2014, Shanghai, China

Malvar M.J.S and Likhitruangsilp V. (2015) A framework of utilizing BIM uses for construction risk management in design-build projects. In Proceedings of International Conference on Civil and Building Engineering Informatics (ICCBEI 2015), 50. Tokyo, Japan, 2015.

Matějka P. and Tomek A. (2014) The impact of BIM on risk management as an argument for its implementation in a construction company. Creative Construction Conference 2014.

Mills, A. (2001) A systematic approach to risk management for construction, Structural Survey, Vol. 19(5), pp. 245-252.

Monteiro A. and Martins J.P. (2013) A survey on modelling guidelines for quantity takeofforiented BIM-based design. Automation in Construction, Vol. 35, pp. 238-353.

Musa A.M., Abanda F.H. and Oti H. (2015) Assessment of BIM for managing scheduling risks in construction project management. Proc. of the 32nd CIB W78 Conference 2015, $27^{\text {th }}-29^{\text {th }}$ October 2015, Eindhoven, The Netherlands.

Musa A.M., Abanda F.H., Oti A.H., Tah J.H.M. and Boton C. (2016) The potential of 4D modelling software systems for risk management in construction projects. $20^{\text {th }}$ CIBWorld Building Congress 2016, May 30 - June 3, Tampere, Finland.

Nieto-Morote, A and Ruz-Vila, F (2011) A fuzzy approach to construction project risk assessment, International Journal of Project Management, Vol. 29, pp. 220-231.

Niño V.M., Clermont P. and Geneste L. (2014) A review of methodologies and tools for project risk management. Twelfth LACCEI Latin American and Caribbean Conference for Engineering and Technology (LACCEI'2014)-Excellence in Engineering to Enhance a Country's Productivity, July 22-24, 2014 Guayaquil, Ecuador.

Oates B.J. (2006) Researching information systems and computing. Sage Publications: London, UK. 
Peterson, T (2009) Case study: Risk management in health care construction projects [online] https://ohsonline.com/Articles/2009/01/01/Case-Study-Risk-Management-in-HealthCare.aspx (Accessed 15 January, 2016).

Polit, D.F and Beck, C.T (2010) Generalization in quantitative and qualitative research: Myths and strategies, International Journal of Nursing Studies, Vol. 47, pp. 1451-1458.

PMI (2013) A guide to the project management body of knowledge (PMBOK), $5^{\text {th }}$ edn. Pennsylvania: Project Management Institute, Inc.

Rao R., Zhang X., Shi Z., Luo K., Tan Z. and Feng Y. (2014) A systematical framework of schedule risk management for power greed engineering projects' sustainable development. Sustainability, Vol. 6, pp. 6872-6901.

Raychaudhuri, S (2008) Introduction to Monte Carlo simulation. Proc. of the 2008 Winter Simulation Conference. [Online] http://www.informs-sim.org/wsc08papers/012.pdf (Accessed 5 April, 2016).

Russell M. M, Howell G, Hsiang S. M and Liu M (2013) Application of time buffers to construction project task durations. Journal of Construction Engineering and Management', Vol. 139(10), doi: 10.1061/(ASCE)CO.1943-7862.0000735.

Sangsomboon, P and Yan, S (2014) Analysis of risk-response based on railroad construction project, International Journal of Management Sciences and Business research, Vol. 3(12), pp. 81-91.

Schieg, M (2006) Risk management in construction project management. Journal of Business Economics and Management, Vol. 7(2), pp. 77-83.

Sigmund, Z and Radujkovic, M (2014) Risk breakdown structure for construction projects on existing buildings, Procedia - Social and Behavioural Sciences, Vol. 119, pp. 894-901

Sun C., Man Q. and Wang Y. (2015) Study on BIM-based construction project cost and schedule risk early warning. Journal of Intelligent and Fuzzy Systems, Vol. 29 (2), pp. 469-477.

Tah J.H.M., Aouad G., Lee A. and Wu S. (undated) Towards information models for risk analysis and management in an $\mathrm{nD}$ modelling environment.

Tah, J.H.M. and Carr, V. (2001a) A knowledge-based approach to construction project risk management. Journal of Computing in Civil Engineering, Vol. 15, No. 3, pp.170-177.

Tah, J.H.M. and Carr, V. (2001b) Towards a framework for project risk knowledge management in the construction supply chain. Advances in Engineering Software, Vol. 32, Nos. 10-11, pp835-846. 
Tah, J.H.M. and Carr, V. (2000a) A qualitative project risk assessment model using fuzzy logic. Journal of Construction Management and Economics, Vol. 18, pp. 491-500.

Tah, J.H.M. and Carr, V. (2000b) Information modelling for project risk analysis and management. Journal of Engineering, Construction and Architectural Management, Vol. 7(2), pp.107-119.

Van Wyk, R ., Bowen, P and Akintoye, A (2008) Project risk management practice: The case of a South African utility company, International Journal of Project Management, Vol. 26(2), pp. 149-163.

Walke R.C. and Topkar V.M (2012) Qualitative analysis of internal and external risks for ready mix concrete plants - A case study approach. Journal of Engineering, Vol. 2(5), pp. 1013-1019.

Wiguna, I.P.A and Scott, S. (2005) Nature of the critical risk factors affecting project performance in Indonesian building contracts. In: Khosrowshahi, F. (Ed.), 21st Annual ARCOM Conference, 7-9 September, SOAS, University of London, Association of Researchers in Construction Management, Vol. 1, pp. 225-235.

Wu I.-C., Lu S.-R. and Hsiung B.-C. (2015) A BIM-based monitoring system for urban deep excavation projects. Visualization in Engineering, Vol. 3 (2).

Zou, P.X.W, Zhang, G. and Wang, J.Y (2006) Identifying key risks in construction projects: life cycle and stakeholder perspectives. In: Proceedings of $12^{\text {th }}$ Pacific-Rim real estate society conference $2006,22^{\text {nd }}-25^{\text {th }}$ January 2006, Auckland, New Zealand.

Zou Y., Kiviniemi A. and Jones S.W. (2015) BIM-based Risk Management: Challenges and Opportunities. Proceedings of the 32nd CIB W78 Conference 2015, $27^{\text {th }}-29^{\text {th }}$ October 2015, Eindhoven, The Netherlands.

Zou Y., Kiviniemi A. and Jones S.W. (2016) A review of risk management through BIM and BIM-related technologies. Safety Science, http://dx.doi. org/10.1016/j.ssci.2015.12.027. 
Appendix 1: Construction risks categories

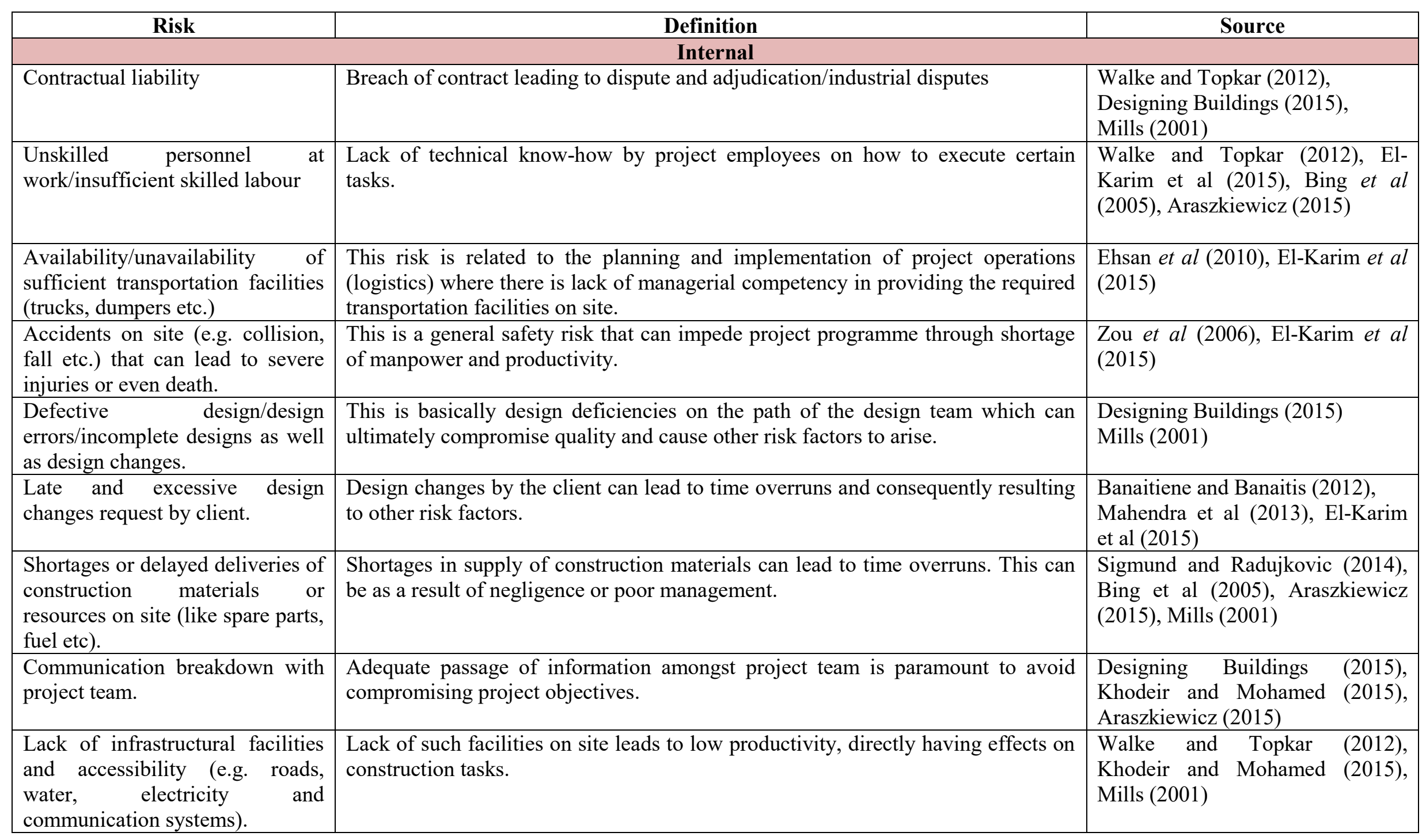




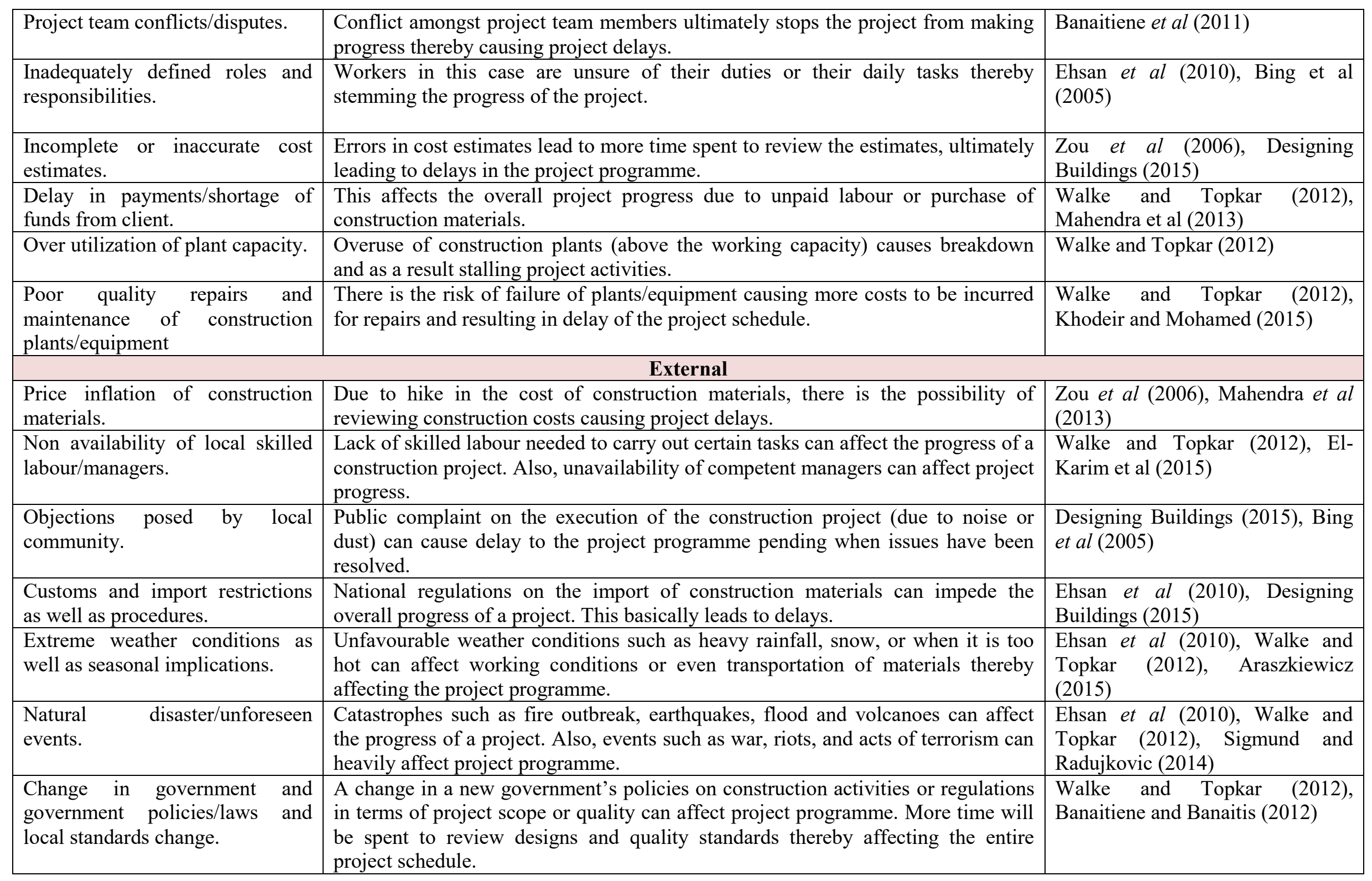




\begin{tabular}{|c|c|c|}
\hline Disease/Epidemic & $\begin{array}{l}\text { An outbreak of a highly contagious and or infectious disease can affect project } \\
\text { progress through low turnout of workers as well as delays in supply of } \\
\text { construction materials. This affects the project schedule. }\end{array}$ & Walke and Topkar (2012) \\
\hline Traffic problems & $\begin{array}{l}\text { In major cities, there can be very high traffic. Such a problem can affect the } \\
\text { delivery of materials to the construction site consequently causing delays in the } \\
\text { programme of works. }\end{array}$ & Walke and Topkar (2012) \\
\hline $\begin{array}{l}\text { Difficulty in obtaining permit and } \\
\text { ordinances. }\end{array}$ & $\begin{array}{l}\text { Complications arising from obtaining building and planning permissions can } \\
\text { affect the overall project schedule resulting in late delivery of the project. }\end{array}$ & $\begin{array}{l}\text { Wiguna and Scott (2005), Bing et } \\
\text { al (2005), Khodeir and Mohamed } \\
(2015)\end{array}$ \\
\hline $\begin{array}{l}\text { Unavailability or scarcity of } \\
\text { plant/equipment spare parts or } \\
\text { fuel. }\end{array}$ & $\begin{array}{l}\text { This risk factor affects repair and/or maintenance routine which eventually causes } \\
\text { delay in some project tasks. This can lead to the project running behind schedule. }\end{array}$ & $\begin{array}{l}\text { Walke and Topkar (2012), Ehsan } \\
\text { et al (2010) }\end{array}$ \\
\hline $\begin{array}{l}\text { Environmental or ecological } \\
\text { issues. }\end{array}$ & $\begin{array}{l}\text { Regulations regarding construction activities that can result in environmental } \\
\text { degradation can jeopardize the entire program of works for a project. }\end{array}$ & $\begin{array}{l}\text { Sigmund and Radujkovic (2014), } \\
\text { Designing buildings (2015) }\end{array}$ \\
\hline $\begin{array}{l}\text { Problems of subsurface } \\
\text { conditions/soil conditions. }\end{array}$ & $\begin{array}{l}\text { Poor ground conditions of a particular site due to soil nature; high water-table or } \\
\text { any other unfavourable condition will mean extra work for workers on site which } \\
\text { can ultimately infringe on the project programme. }\end{array}$ & $\begin{array}{l}\text { Assaf and Al-Hejji (2006), Bing et } \\
\text { al (2005), Mills (2001) }\end{array}$ \\
\hline $\begin{array}{l}\text { Problems/delays in providing } \\
\text { services from utility companies } \\
\text { (like water and electricity). }\end{array}$ & $\begin{array}{l}\text { Problems/shortages/delays in the provision of major utilities required to execute } \\
\text { activities can hinder the progress of the overall project thereby causing delays in } \\
\text { the project schedule. }\end{array}$ & $\begin{array}{l}\text { Assaf and Al-Hejji (2006), Bing et } \\
\text { al (2005) }\end{array}$ \\
\hline Transport strike & $\begin{array}{l}\text { Public transportation workers, strike can heavily cause inconveniencies for people, } \\
\text { affecting their movements to carry out their daily routine. This can result in } \\
\text { workers turning out late to work affecting project schedule. }\end{array}$ & Walke and Topkar (2012) \\
\hline
\end{tabular}


